\title{
Platform pricing and consumer foresight: The case of airports*
}

\author{
Ricardo Flores-Fillol $^{\dagger} \quad$ Alberto Iozzi ${ }^{\ddagger} \quad$ Tommaso Valletti ${ }^{\S}$
}

December 20, 2017

\begin{abstract}
We analyze the optimal behavior of a platform providing essential inputs to downstream firms selling a primary and a second complementary good. Final demand is affected by consumer foresight, i.e., consumers may not anticipate the ex post surplus from the secondary good when purchasing the primary good. We first set up a reduced-form platform model and evaluate the effects of consumer foresight on the platform's optimal decisions. Then, we specialize the analysis in the context of airports, which derive revenues from both aeronautical and, increasingly, commercial activities. An airport sets landing fees and, in addition, it chooses the retail market structure by selecting the number of retail concessions to be awarded. We find that, with perfectly myopic consumers, the airport chooses to attract more passengers via low landing fees, and also sets the minimum possible number of retailers in order to increase the concessions' revenues. However, even a very small amount of anticipation of the consumer surplus from retail activities changes significantly the airport's choices: the optimal policy is dependent on the degree of differentiation in the retail market. When consumers instead have perfect foresight, the airport establishes a very competitive retail market. This attracts passengers and it is exploited by the airport by charging higher landing fees, which then constitute the largest share of its profits. Overall, the airport's profits are maximal when consumers have perfect foresight.
\end{abstract}

Keywords: two-sided markets, platform pricing, one-way demand complementarity, consumer foresight.

JEL classification: L1, L2, L93.

${ }^{*}$ We are grateful to Leo Basso, Jan Brueckner, Achim Czerny, Tiziana D'Alfonso, Walter Ferrarese, Anming Zhang, and audiences in Amsterdam (Option Conference), Barcelona (Jornadas de Economía Industrial and Meeting on Transport Economics and Infrastructure), Bolzano-Bozen (Free U. of Bozen), Hong Kong (Hong Kong Polytechnic U.), Munich (EARIE Conference), Oslo (ITEA Conference), Pescara (U. di Chieti-Pescara), Reus (International Conference on Regional Science, Trobada URV-UA, and INFER Annual Conference), Turin (Workshop NERI), and Valencia (Workshop ANAECO) for very useful comments. The usual disclaimers apply.

${ }^{\dagger}$ Departament d'Economia and CREIP, Universitat Rovira i Virgili: ricardo.flores@urv.cat.

‡Università di Roma 'Tor Vergata’ and SOAS University of London: alberto.iozzi@uniroma2.it.

§Imperial College London, Università di Roma 'Tor Vergata' and CEPR: t.valletti@imperial .ac.uk. 


\section{Introduction}

The airport business is increasingly becoming a platform activity. Airports derive revenues not only from the traditional aeronautical activities, but also from the commercial activities taking place at the terminals, such as shops, food and beverage and car parks. The Economist (2014) refers to airport shopping as the 'sixth continent' to highlight its importance. According to industry reports, airports achieve at least $50 \%$ of their revenues from non-aeronautical activities, with retail representing the main source (ACI, 2012; ATRS, 2014). Massive investments have supported this trend, with airports increasing their dutyfree space significantly. In 2008, the project at Beijing Airport T3 was completed with the design of the star architect Norman Foster and a staggering floor space of 1,000,000 sqm. It was the largest terminal in the world, soon to be surpassed by Dubai International Airport's T3, which is twice as large.

To do their shopping at airports, passengers need to buy a flight ticket first. This decision is influenced by airfares, which, in turn, are affected by the landing fee charged by airports. A role is also played by the anticipation of the utility that can be derived from shopping at the airport. Indeed, according to Mintel, about 20\% of British and German leisure travelers anticipate airport shopping. Asian-pacific international travelers are also committed shoppers (Mintel, 2013). These are different from impulse buyers.

Thus, in general, aeronautical and commercial revenues are interdependent. Landing fees generate aeronautical revenues but also have a sizeable external effect on the airport retail activities by affecting the number of passengers making use of the airport facilities. An increase in the landing fee may have a positive effect on the aeronautical revenues but, at the same time, a countervailing negative effect on commercial revenues due to the reduction in the number of passengers. On the other hand, when consumers anticipate airport shopping, commercial activities can attract flyers and, therefore, increase aeronautical revenues.

We propose a model to study the optimal strategy of an airport platform that can generate revenues both from traditional aeronautical activities and from non-aviation (retail) activities. Should an airport use its market power to set high landing fees, even though this may shrink the demand for commercial services? Should the airport allow for several concessions for similar services, or should it instead limit within-airport competition by awarding few concessions, thus enhancing the revenues that can be extracted from concessionaires? The answer must lie in unraveling the extent to which a better customer experience at the terminal can enhance the demand for flight services.

Our model introduces three important contributions to the airport literature. First, we make explicit the one-way complementarity between the demand for air travel and retail products. While this link is already present in other models, its role has not been 
investigated in depth. In our setting, air services are bought by consumers as a primary product, while retail services play the role of the secondary product, being demanded exclusively by those who consume the primary product. Second, we introduce what we call the degree of consumer foresight, i.e., the extent to which passengers anticipate, at the time of purchasing their flight, the retail surplus they will obtain at the terminal. Third, our paper is the first to recognize the endogenous nature of the retail market structure, which is determined by the airport. ${ }^{1}$

We derive the demand functions for air travel and retail services, where the demand for air travel depends on the surplus that the consumer anticipates to obtain from the consumption of the retail good. Then we perform a two-stage equilibrium analysis. In the first stage, the airport sets the landing fee and chooses the number of retailers allowed to operate concessions. In the second stage, retailers and airlines compete. We first look at this problem in a general set-up in which we leave the modes of downstream competition unspecified and impose minimal restrictions on consumer preferences; this analysis illustrates the general relevance of our approach. We then turn to analyze a specific model to better illustrate the airport case.

Our main findings can be summarized as follows. In the presence of perfectly myopic consumers, the airport chooses the minimum possible number of retailers and a landing charge lower than the standard monopoly charge. The airport exploits the complementarity between aeronautical and retail activities by attracting more passengers to the terminal by setting low landing fees. Maximum retail profits are extracted, with no impact on the ex ante demand for flights.

In the other extreme case with perfectly forward looking consumers, the relative importance of the two revenue sources is reversed. The airport chooses a very competitive retail sector, which expands the demand for air travel since consumers anticipate the benefits they will receive from purchases at the terminal. Thus, the airport can charge higher landing fees and makes most of its profits from the aeronautical business.

In the case of limited myopia, the result depends on the degree of product differentiation in the retail sector. When there is little differentiation, strong retail competition makes the retail business less attractive to the airport, so that the airport prefers the most concentrated retail structure, but it also raises the landing fee (as compared to the case with perfectly myopic consumers) since some retail consumer surplus is now anticipated by

\footnotetext{
${ }^{1}$ Although the airport chooses the landing fee to be charged to airlines, it has a limited capacity (sometimes no capacity at all) to determine the airline market structure. In Europe, airports have no power to determine the airline market structure since the use of slots is based on rules such us 'grandfather rights' (i.e., an operator which currently uses a slot can retain the slot each period) or 'use-it-or-lose-it' rules (i.e., airlines must operate slots as allocated by the coordinator at least $80 \%$ of the time during a season to retain historical rights to the slots; see Gale and O'Brien, 2013).
} 
air travelers. When differentiation is large, the airport instead prefers not to derive profits from aeronautical services (thus setting landing fees to zero) and boosts the expected consumer surplus by awarding a certain number of concessions to additional retailers.

In equilibrium, we find that the highest aggregate profits are obtained when consumers have perfect foresight. As illustrated above, the balance of the airport's aeronautical and retail profits changes dramatically with the degree of consumer foresight.

Beyond airports: other platform settings. While airports represent the motivation for our analysis of platform pricing, it is easy to think of other settings to which the model could be applied, with suitable adaptations. In general terms, we consider an intermediary supplier that derives revenues from a core good and a second strictly complementary good. We describe a situation where the core good is more 'salient' in the initial purchasing decision, compared to the side good's consumption that can be decided after the initial purchase. In the case of airports, the core good is a flight, while the side good is some retail activity at the terminal; saliency here corresponds to our notion of consumer foresight.

The platform cannot control directly the price of these two goods, but it can influence them. It affects the wholesale cost of the primary good and the intensity of competition for the secondary good. If consumers' purchase of the core good is inelastic with respect to the price of the secondary good, the platform has an interest to extract as much profit as possible ex post from the side good (by making the secondary market as concentrated as possible), while the wholesale price for the core good should be kept down to attract customers to the market. If the cross-price elasticity differs from zero, incentives change. The secondary market should be made more competitive in order to expand demand for the primary product. Then, the platform pushes up the wholesale price in the primary market. The cross-price elasticity depends on consumers' preferences and on their expectations about future purchases of the secondary good. Our model aims at making these intuitive and general arguments accurate, and derived from first principles.

The generality of this approach applies to many settings. People go to shopping malls for a primary activity (e.g., going to a movie theater) but may end up also purchasing a secondary good (a meal, or some other shopping); hotels charge for rooms, but may also additionally sell in-room services (telephone calls, laundry, meals) that are not necessarily anticipated when booking a room; videogame consoles are bought based also on some predictions that consumers make about games that will be developed for those consoles.

In these examples, the degree of vertical integration and delegation varies (e.g., for hotels, most secondary goods are directly supplied by the supplier of the primary product) but the question of market structure is still of general interest. For shopping malls, the setting for the secondary product is very close to ours: the mall chooses the type of retailers, 
but cannot determine directly their price. Fittingly, game console makers price their core platform good to encourage adoption while trying to manage the market structure of game developers around their platform. Generally, platform providers have to decide whether to make their platform open (which makes entry of side goods easier, leading to competitivelypriced secondary products) or closed (in which case the platform would try to share the rents that could eventually accrue to the side good providers, e.g., by proposing exclusivity fees). While each setting would have its distinguishing features, our model is useful generally to think about these other environments too.

The paper is organized as follows. In Section 2 we relate our paper to the existing literature. In Section 3 we abstract from the specificities of airports, and study a reduced-form model of a platform that derives profits from two complementary goods. In Section 4 we present a more specific airport model and derive the demand functions for air travel and for retail services. Then in Section 5 we perform the equilibrium analysis, distinguishing between the cases of perfectly myopic consumers, almost myopic consumers, and forward looking consumers; also, we examine the airport's profits and derive managerial implications. Finally, Section 6 concludes. Proofs are provided in the Appendix.

\section{Literature review}

The two-sided platform nature of airports is often cited (Zhang and Zhang, 1997; Starkie, 2001; Wright, 2004; Czerny, 2006; Van Dender, 2007; Gillen and Mantin, 2012; and Ivaldi et al., 2015), although few formal treatments exist. ${ }^{2}$ To our knowledge, this is the first paper to study an airport's optimal pricing strategy to both sides, including the optimal retail market structure.

As compared to other platforms, airports have their own peculiarities derived from the one-way complementarity between the demand for air services (primary good) and retail services offered at the terminals (secondary good). In our model, at the moment of purchasing the flight ticket, consumers may not fully anticipate the surplus they will obtain from the retail good once at the airport. This incomplete anticipation may be the result of several phenomena. First, consumers may suffer from myopia that makes them unable to take into account future purchases when buying the primary good. This is in line with a number of studies studying the issue of limited rationality in solving consumption problems (Busse et al., 2013). Second, rational consumers purchasing more than one product may not be fully informed on the terms prevailing in all the markets

\footnotetext{
${ }^{2}$ There is instead a different literature on airport congestion pricing that we do not review here for lack of space. The first papers to study two-sided markets are Caillaud and Jullien (2003), Armstrong (2006), and Rochet and Tirole (2003).
} 
(Lal and Matutes, 1994; Gans and King, 2000). For instance, Hagiu and Halaburda (2014) consider a two-sided platform connecting developers and users (e.g., videogame consoles), where developers have full information about all prices and users may be either informed (i.e., holding responsive expectations) or uninformed (i.e., holding passive expectations). In the latter case, uninformed users rely on external information to form expectations about the number of developers and do not adjust them in response to changes in platform prices.

A further source of imperfect anticipation of the retail surplus could be due to the fact that, before arriving at the terminal, consumers are assumed not to know for certain their preferences for the retail good. This feature of our model is also shared in other contexts. For instance, in behavioral economics, there are papers where uninformed consumers do not know their ideal taste ex ante and, thus, they are uncertain as to which product they will finally buy (Heidhues and Köszegi, 2009; and Karle and Peitz, 2014).

A large body of literature has studied markets with primary and secondary goods (or, with alternative definitions, markets with aftermarkets, or markets for standard goods and add-ons). This issue has been tackled by Oi's (1971) classic study of two-part pricing by a Disneyland monopolist, where he concludes that the firm can extract completely the consumer surplus with the fixed admission fee, while setting the price of rides at marginal cost. Although we obtain a similar result when consumers are sufficiently forward-looking, this result breaks down as consumers exhibit a certain degree of myopia. Our model departs from this literature in three ways. First, prices for the secondary good are not set by the monopolist, but are determined by independent retailers. The only way the airport has to affect retail prices is via the number of concessions. Second, the surplus consumers derive from the secondary goods does not depend only on their prices, like in Oi, but also on the number of varieties (i.e., concessions) and, therefore, on product differentiation. Third, we study explicitly the role of consumer foresight, which is not part of Oi's analysis.

Some studies have looked at the problem of primary and secondary products with different consumer types (Ellison, 2005; and Gabaix and Laibson, 2006). Two general findings should be recalled. First, the distortion on prices is larger the lower is the degree of demand complementarity, the less able are the consumers to forecast future prices, and the more different are the consumers' types. Second, the platform's profitability is higher the less able are the consumers to anticipate the net benefits they obtain from the secondary good.

Our problem shows similarities with the vast literature on shopping malls (see Carter, 2009, for a survey). Part of this literature is concerned with the instruments to internalize the externalities between the different outlets within a shopping mall, and between the shopping mall and the neighboring activities/properties. The most commonly investigated instruments are the composition of the commercial outlets (Hagiu, 2009), the nature of the contracts between the landlord and the commercial outlets (Miceli and Sirmans, 1995; 
Pashiman and Gould, 1998), the allocation of space within the shopping mall (Brueckner, 1993), and its geographical locations (Carter and Vandelland, 2006).

Our paper can also be linked to the literature on platforms studying when technological hubs should be open (Boudreau, 2010) or when additional content should be given for free (Hagiu and Spulber, 2013). We share the view that retail activities can be made more or less competitive, which is equivalent to making the platform more 'open' to complementary products. The difference is that, in our setting, the consumer purchases only one retail product ex post and, therefore, there is not a demand-expansion channel for the platform leading to an increased retail activity because customers purchase more products. Instead, in our model, retail activities can affect ex ante consumer surplus from expected retail prices.

\section{A general platform model with complementary goods and consumer foresight}

The purpose of this section is to analyze the effect of consumer foresight on a platform's decisions in a general setting with complementary goods. Let us consider the related markets $A$ (a mnemonic for air travel) and $R$ (a mnemonic for retail), where $A$ is a core good and $R$ is a side good that can only be consumed once the core good has been purchased. The platform operates in both markets, in which downstream firms sell to final consumers at prices $p_{A}$ and $p_{R}$, with corresponding quantities denoted by $Q_{A}$ and $Q_{R}$. We first describe consumer preferences and demand and then examine the platform's optimal choices.

The consumer problem. We consider a representative consumer with a quasi-linear utility over a core and a side good (full details in Appendix B). $R$ 's demand is assumed to be proportional to the one for $A$, so that

$$
Q_{R}=y\left(p_{R}\right) Q_{A}
$$

where $y\left(p_{R}\right)$ denotes the proportion and satisfies $y^{\prime}\left(p_{R}\right)<0$. The optimal choice of $Q_{R}$ can be embodied in the consumer problem, who then chooses $Q_{A}$ to maximize a utility function

$$
g\left(Q_{A}\right)+Q_{A}\left[\delta C S\left(p_{R}\right)-p_{A}\right]
$$

where $g(\cdot)$ is the stand-alone utility from consuming the core good, with $g^{\prime}>0$ and $g^{\prime \prime}<0$, and $C S\left(p_{R}\right)$ denotes the consumer surplus from the side good per unit of the core good, with $C S^{\prime}\left(p_{R}\right)=-y\left(p_{R}\right)$. The parameter $\delta \in[0,1]$ tells how much the consumer takes into 
account the utility derived from the consumption of the side good when purchasing the core good. If $\delta=0$, the core good is bought based on the utility the consumer derives strictly from it. Instead, if $\delta=1$, the consumer fully anticipates the utility derived from the side good. Values between 0 and 1 denote intermediate cases. ${ }^{3}$

The first-order condition with respect to $Q_{A}$ yields

$$
g^{\prime}\left(Q_{A}\right)+\delta C S\left(p_{R}\right)-p_{A}=0
$$

Expressions (1) and (3) implicitly define total demand for the core and the side good. By totally differentiating them with respect to $p_{A}$ and $p_{R}$, we obtain

$$
\frac{\partial Q_{A}}{\partial p_{A}}=\frac{1}{g^{\prime \prime}\left(Q_{A}\right)}<0 \quad \text { and } \quad \frac{\partial Q_{A}}{\partial p_{R}}=\frac{\delta y\left(p_{R}\right)}{g^{\prime \prime}\left(Q_{A}\right)} \leqslant 0
$$

which allows us the compute and sign the following elasticities

$$
\epsilon_{A} \equiv \frac{\partial Q_{A}}{\partial p_{A}} \frac{p_{A}}{Q_{A}}=\frac{p_{A}}{g^{\prime \prime}\left(Q_{A}\right) Q_{A}}<0 \quad \text { and } \quad \epsilon_{A R} \equiv \frac{\partial Q_{A}}{\partial p_{R}} \frac{p_{R}}{Q_{A}}=\frac{\delta y\left(p_{R}\right) p_{R}}{g^{\prime \prime}\left(Q_{A}\right) Q_{A}} \leqslant 0
$$

The platform's optimal choices. The platform employs different instruments in each market. While it sells the input at a linear unit price $\ell$ in market $A$, it sets the number $n_{R}$ of firms in market $R$ and extracts their profits, e.g., by means of a first-price auction among a large number of identical firms. The marginal cost of the input sold in market $A$ is denoted by $c$, while the access cost to market $R$ is normalized to 0 .

To study the platform behavior, we set up a two-stage game. First, the platform chooses $\ell$ and $n_{R}$. Second, there is downstream competition in each market. Let $p_{R}\left(n_{R}, \ell\right)$ and $p_{A}\left(\ell, n_{R}\right)$ be the second-stage equilibrium prices. Consistent with reasonable models of competition, we posit $\frac{\partial p_{R}}{\partial n_{R}}<0$ and $\frac{\partial p_{A}}{\partial \ell}>0$, i.e., more competition pushes prices down in market $R$ and a higher input cost pushes up the final price in market $A$. As to the cross-market effects, their signs depend on the nature of the interaction between markets $A$ and $R$. We assume $\frac{\partial p_{A}}{\partial n_{R}} \geqslant 0$ and $\frac{\partial p_{R}}{\partial \ell} \leqslant 0$, so that downstream firms react by pushing down their own price when the complementary good is more expensive. However, both effects vanish when consumers are perfectly myopic. Hence, $\left.\frac{\partial p_{A}}{\partial n_{R}}\right|_{\delta=0}=0$, because the market for the side good does not affect the demand for the primary good; and $\left.\frac{\partial p_{R}}{\partial \ell}\right|_{\delta=0}=0$, because $R$ is a replica market with a proportional demand and $y\left(p_{R}\right)$ is not affected by changes in

\footnotetext{
${ }^{3}$ Notice that we are silent as to whether (2) represents the actual utility or the perceived utility of a consumer, as a function of $\delta$. This distinction does not matter for the positive analysis we develop in this paper, but it would once one tackles welfare and regulatory questions. Developing a non-paternalistic method of welfare analysis in behavioral models is an open challenge (see Chetty, 2015).
} 
quantities of the core good. ${ }^{4}$ At this point, it is useful to define

$$
\sigma_{A \ell} \equiv \frac{\partial p_{A}}{\partial \ell} \frac{\ell}{p_{A}}>0 ; \quad \sigma_{R \ell} \equiv \frac{\partial p_{R}}{\partial \ell} \frac{\ell}{p_{R}} \leqslant 0 ; \quad \sigma_{A n} \equiv \frac{\partial p_{A}}{\partial n_{R}} \frac{n_{R}}{p_{A}} \geqslant 0 ; \quad \sigma_{R n} \equiv \frac{\partial p_{R}}{\partial n_{R}} \frac{n_{R}}{p_{R}}<0 .
$$

The first two expressions are pass-through coefficients expressed in elasticity form, which illustrate the sensitivity of the price in the final market to a change in the input cost in the core good market. A similar interpretation can be given to the last two expressions where, however, the varying parameter is the number of downstream firms.

In the first stage, the platform anticipates the equilibrium in the downstream markets and chooses $n_{R}$ and $\ell$ to maximize its profits $\Pi$. Using (1), this problem becomes

$$
\begin{aligned}
& \max _{\ell, n_{R}} \Pi=\left[\ell-c+p_{R} y\left(p_{R}\right)\right] Q_{A} \\
& \text { s.t. } p_{R}=p_{R}\left(\ell, n_{R}\right) \text { and } p_{A}=p_{A}\left(\ell, n_{R}\right),
\end{aligned}
$$

and the first-order conditions yield

$$
\begin{aligned}
\frac{\partial \Pi}{\partial \ell} & =\left(\frac{\partial Q_{A}}{\partial p_{A}} \frac{\partial p_{A}}{\partial \ell}+\frac{\partial Q_{A}}{\partial p_{R}} \frac{\partial p_{R}}{\partial \ell}\right)\left[\ell-c+p_{R} y\left(p_{R}\right)\right]+Q_{A}\left[1+\frac{\partial p_{R}}{\partial \ell}\left[y\left(p_{R}\right)+p_{R} y^{\prime}\left(p_{R}\right)\right]\right] \\
\frac{\partial \Pi}{\partial n_{R}} & =\left(\frac{\partial Q_{A}}{\partial p_{A}} \frac{\partial p_{A}}{\partial n_{R}}+\frac{\partial Q_{A}}{\partial p_{R}} \frac{\partial p_{R}}{\partial n_{R}}\right)\left[\ell-c+p_{R} y\left(p_{R}\right)\right]+Q_{A} \frac{\partial p_{R}}{\partial n_{R}}\left[y\left(p_{R}\right)+p_{R} y^{\prime}\left(p_{R}\right)\right]
\end{aligned}
$$

Next, we analyze and compare these two conditions first in the case of fully myopic consumers and then when consumers are foresighted.

Fully-myopic consumers $(\delta=0)$. In this case, the cross-price effect $\frac{\partial Q_{A}}{\partial p_{R}}$ is equal to zero; also, $\frac{\partial p_{A}}{\partial n_{R}}=\frac{\partial p_{R}}{\partial \ell}=0$, as the decisions of the platform in one market have no effect on the other. Using (5) and (6), the above first-order conditions simplify to

$$
\begin{gathered}
\frac{\ell-\left[c-p_{R} y\left(p_{R}\right)\right]}{\ell}=-\frac{1}{\epsilon_{A} \sigma_{A \ell}}, \\
\frac{\partial p_{R}}{\partial n_{R}}\left[y\left(p_{R}\right)+p_{R} y^{\prime}\left(p_{R}\right)\right]<0,
\end{gathered}
$$

and give rise to the following observation.

Claim 1. When consumers are fully myopic, the platform sets $\ell$ below the standard monopoly price and $n_{R}$ as low as possible.

\footnotetext{
${ }^{4}$ In the Online Appendix, we analyze the case of heterogeneous consumers with correlated preferences, so that $\frac{\partial p_{R}}{\partial \ell} \lesseqgtr 0$ can be observed for any value of $\delta$. We thank the Co-Editor and a referee for suggesting this extension to our analysis.
} 
Expression (10) shows that the platform sets an almost standard monopoly price in market $A$, choosing a mark-up inversely related to the superelasticity $\epsilon_{A} \sigma_{A \ell}$, which illustrates the effect on $Q_{A}$ of a change in $\ell$ through $p_{A}$. The feature that distinguishes this expression from a standard mark-up is the term $p_{R} y\left(p_{R}\right)$ in the left-hand side, which pushes down the marginal cost in recognition of the higher profits a lower $\ell$ induces in market $R$ because of the proportional expansion of demand. Hence, the platform sets a price $\ell$ below the standard monopoly price in the primary market and, possibly, below cost. In the secondary market, (11) implies that the monopolist sets $n_{R}$ as low as possible (achieving the most concentrated market structure), since $y\left(p_{R}\right)+p_{R} y^{\prime}\left(p_{R}\right)>0$ captures the marginal revenue in the secondary market with respect to $p_{R} .^{5}$

Foresighted consumers $(\delta>0)$. In this case, using (5) and (6), (8) becomes

$$
\frac{\ell-\left[c-p_{R} y\left(p_{R}\right)\right]}{\ell}=\underbrace{-\frac{1}{\epsilon_{A} \sigma_{A \ell}+\epsilon_{A R} \sigma_{R \ell}}\left[1+\frac{\partial p_{R}}{\partial \ell}\left[y\left(p_{R}\right)+p_{R} y^{\prime}\left(p_{R}\right)\right]\right]}_{>0 \text { for a sufficiently large demand expansion effect }},
$$

where the novelties with respect to $(10)$ are $i$ ) the superelasticity of demand for $Q_{A}$ with respect to $\ell$, which now incorporates the effect on $Q_{A}$ of change in $\ell$ also through $p_{R}$ $\left(\epsilon_{A R} \sigma_{R \ell}\right)$, and $\left.i i\right)$ the expression $\left[1+\frac{\partial p_{R}}{\partial \ell}\left[y\left(p_{R}\right)+p_{R} y^{\prime}\left(p_{R}\right)\right]\right]$, which illustrates the effect on the revenues from the side good when $\ell$ changes. Since $\frac{\partial p_{R}}{\partial \ell}<0$ and $\epsilon_{A} \sigma_{A \ell} \lessgtr \epsilon_{A R} \sigma_{R \ell}$, the entire right-hand side can be of either sign. An increase in $\ell$ reduces $p_{R}$ and the revenues from the side market, but also triggers an increase in the surplus that can be expected in market $R$, thus pushing up demand (and price) in market $A$ (as given by $\epsilon_{A R}$ ). This demand expansion effect becomes more significant the larger are $\frac{\partial p_{R}}{\partial \ell}$ and $\epsilon_{A R}$ (in absolute terms), where the latter increases with the degree of consumer foresight (see (5)). From these findings, we derive the next observation.

Claim 2. The larger is the degree of consumer foresight, the larger is the demand expansion effect that makes the platform choose $\ell$ above its adjusted marginal cost.

Substituting (12) into (9) and using (5) and (6), the first-order condition in (9) becomes

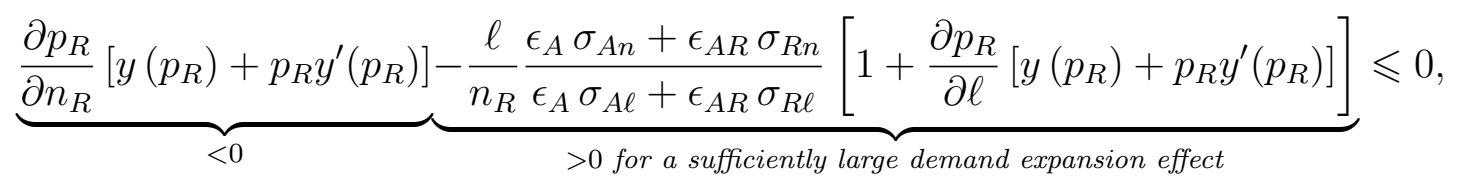

where the novelty with respect to (11) is found in the second term. This term includes a ratio between superelasticities that captures the effect on $Q_{A}$ of a change in $n_{R}$ in the numerator and that of a change in $\ell$ in the denominator. As in (12), when $\frac{\partial p_{R}}{\partial \ell}$ and $\epsilon_{A R}$ are

\footnotetext{
${ }^{5}$ Similar results are found in Nocke et al. (2007) and Hagiu (2009).
} 
large (in absolute terms), a change in $\ell$ has a significant positive impact on $A$ 's demand, i.e., the demand expansion effect is large. When this effect is sufficiently large, the whole second term becomes positive, inducing the platform to set $n_{R}$ above its minimum value. Since the demand expansion effect increases with $\delta$, the following observation can be formulated.

Claim 3. The larger is the degree of consumer foresight, the larger is the demand expansion effect that makes the platform choose a more fragmented market structure for the side good.

In conclusion, when consumers are myopic, the platform chooses a concentrated side good market structure and an input price $\ell$ lower than the standard monopoly price. However, a sufficiently large degree of consumer foresight triggers a demand expansion effect that makes the platform choose optimally a higher input price $\ell$ along with a more fragmented side-good market structure (i.e., a larger $n_{R}$ ).

Having identified the key mechanisms, which are independent of modeling assumptions, the section that follows puts more structure on the model. We propose an airport-specific model, where $A$ and $R$ denote the aeronautical and retail businesses. The advantage is that some clear analytical solutions can be derived directly from first principles.

\section{A specific platform model of an airport}

An airport provides both aeronautical and retail services. Aeronautical services are sold to $n_{A}$ airlines competing $\grave{a}$ la Cournot; airlines pay a per-passenger landing fee $\ell$ to the airport for the use of the infrastructure. The airport also chooses the number of concessions $n_{R}$ to be awarded to retailers that trade in the airport commercial area. Retailers are symmetrically located along a Salop circle of unit length and compete by setting prices.

Passengers derive their utility from the consumption of flights and retail goods. Their decisions are made in a two-step process: first, they purchase their flight tickets; second, they make their retail purchases once at the airport. Hence, only passengers who fly may also buy the retail goods (but not vice versa).

We consider a two-stage game model with the following timing. In the first stage, the airport sets a landing charge and selects the number of retailers. In the second stage, airlines compete by choosing simultaneously and non-cooperatively their quantities, and retailers simultaneously and non-cooperatively set their prices. Once these decisions are made, passengers make their flight and retail purchases, and payoffs are collected. We analyze a game of full information and use subgame perfection as the equilibrium concept.

Air travel demand. Each passenger is characterized by a parameter, $z$, which illustrates the utility she derives from consuming the (homogeneous) air service. The utility of a 
potential passenger is $U\left(p_{A}, \boldsymbol{p}_{R} ; z, \delta\right)=z+\delta C S\left(\boldsymbol{p}_{R}\right)-p_{A}$, where $p_{A}$ is the airfare and $\boldsymbol{p}_{R}=\left(p_{1}, p_{2}, \ldots, p_{n_{R}}\right)$ is the vector of prices set by the $n_{R}$ retailers; $z$ is the benefit a passenger receives when traveling, uniformly distributed over the support $[-a, 1]$, with unit density. ${ }^{6}$ Note that $C S\left(\boldsymbol{p}_{R}\right)$ is the expected retail surplus that the consumer anticipates to derive from the consumption of the retail good (to be discussed later). ${ }^{7}$ As in the general model in Section 3, $\delta \in[0,1]$ tells how much the consumer takes into account the utility derived from the consumption of the retail good when making her flight purchase decision.

Each consumer purchases at most one flight ticket, as long as her net utility is nonnegative, i.e., $U(\cdot) \geqslant 0$. Let $\widetilde{z}$ be the flight utility parameter of the consumer that is just indifferent between flying and not flying. Then, the aggregate demand for flights (i.e., the number of passengers traveling from the airport) is

$$
Q_{A}\left(p_{A}, \boldsymbol{p}_{R} ; \delta\right)=1-\widetilde{z}\left(p_{A}, \boldsymbol{p}_{R} ; \delta\right)=1-p_{A}+\delta C S\left(\boldsymbol{p}_{R}\right)
$$

whenever this is positive. ${ }^{8}$

Retail market demand. The $n_{R}$ retailers sell an homogeneous good and are symmetrically distributed on a Salop circle of length 1 , with $n_{R} \geqslant 2 .{ }^{9}$ Since access to the retail market is only available to passengers, the mass of potential consumers is $Q_{A}\left(p_{A}, \boldsymbol{p}_{R}\right)$. Each consumer has a unit demand and a taste parameter $x$ for the retail good, which is uniformly distributed over the support $[0,1]$ and is taken to be her position along the circle. ${ }^{10}$

For a consumer located at $x$, retail utility when buying from the nearby retail firm located in $x_{i}$ is $u=v-p_{i}-t\left|x-x_{i}\right|$. We assume that $v$ is always sufficiently high so that

\footnotetext{
${ }^{6}$ The lower bound of the support, $a$, is assumed to be large enough so that the passengers' market is never fully covered and airlines demand is elastic.

${ }^{7}$ It is possible to imagine a different nature of the consumer's expectations with respect to the retail surplus. For instance, following Hagiu and Halaburda (2014), consumers could have passive expectations about retail prices that are fulfilled in equilibrium. In this alternative set-up, most of our results would carry over. Details are available from the authors upon request.

${ }^{8}$ Alternatively, we could have considered an heterogeneous population with a fraction $\eta$ of perfectly foresighted consumers and a fraction $(1-\eta)$ of perfectly myopic consumers. The cut-off utility parameter $\widetilde{z}(\cdot)$ would become $p_{A}-C S\left(\boldsymbol{p}_{R}\right)$ for foresighted consumers and $p_{A}$ for myopic ones. The aggregate demand for flights would become $Q_{A}\left(p_{A}, \boldsymbol{p}_{R} ; \delta\right)=\eta\left[1-p_{A}+C S\left(\boldsymbol{p}_{R}\right)\right]+(1-\eta)\left(1-p_{A}\right)=1-p_{A}+\eta C S\left(\boldsymbol{p}_{R}\right)$, identical to (14), where $\eta$ can be reinterpreted as the average degree of foresight. Therefore, as long as both types of consumers are served, this approach would be equivalent to our representative consumer specification. The advantage of our approach is to avoid having to look at the uninteresting extreme cases whereby only one type of consumer is targeted.

${ }^{9} \mathrm{We}$ could allow for a monopolist retailer, but the monopoly price would be analytically different from the one in case of 2 or more firms. Having $n_{R} \geqslant 2$ avoids this case distinction, not central for our analysis.

${ }^{10}$ We consider a retail market in which all retailers offer goods which are substitute to one other. In reality, one may find many non-substitutable products at any airport terminals, like food and clothing. A simple way to include this feature in our model would be to imagine several Salop circles, each one for retailers selling goods which are substitute to one other but not to goods offered by other retailers located on a different circle. In this case, we could easily endogenise the number of non-competing varieties (i.e., the number of circles). This extension would magnify the effect of the retail activities in our model.
} 
the market is fully served. As it will become clear at a later stage, this implies

$$
v>\frac{5}{8} t
$$

Retailers' demand and profits are derived in the standard way. ${ }^{11}$ Focus on retailer $i$, assumed w.l.o.g. to be located at 0 , and consider that all rivals are symmetrically located. The marginal consumer between firm $i$ and one of its nearest rivals, say firm $j$, is $\widetilde{x}_{i j}=$ $\frac{1}{2 n_{R}}+\frac{p_{j}-p_{i}}{2 t}$. Assuming symmetry in the prices set by all the rival firms to firm $i$, the demand for $i$ becomes $X_{i}\left(p_{i}, p_{j} ; \boldsymbol{p}_{R}\right)=2 \widetilde{x}_{i j}\left(p_{i}, p_{j}\right) Q_{A}\left(p_{A}, \boldsymbol{p}_{R}\right)$. After normalizing retailers' costs to 0 , retailer $i$ 's profits are

$$
\pi_{i}=p_{i} X_{i}\left(p_{i}, p_{j} ; \boldsymbol{p}_{R}\right)=p_{i}\left(\frac{1}{n_{R}}+\frac{p_{j}-p_{i}}{t}\right)\left[1-p_{A}+\delta C S\left(\boldsymbol{p}_{R}\right)\right]
$$

The above expression makes it clear that retail profits depend on the number of passengers which, in turn, depends on their retail surplus expectation.

When deciding whether or not to buy the flight ticket, consumers are not yet aware of their taste parameter (the location $x$ on the unit circle). In other words, a passenger does not know in advance whether she will want, say, to spend time in a restaurant for a meal or simply go to a bar for a coffee, as this depends on contingencies that cannot be foreseen when booking the flight. Only on the day of the flight, this will be revealed. Still, a passenger may anticipate she will want either a coffee or a meal on the day she flies. Therefore, passengers are able to form an expectation of the surplus they will be able to enjoy. Passengers' priors consider that each location along the Salop circle is equally likely. Hence, the value of the expected surplus when one retailer charges $p_{i}$ and all other retailers charge symmetrically $p_{j}$ (let $\boldsymbol{p}_{j}$ denote the vector of these prices) is

$$
C S\left(p_{i}, \boldsymbol{p}_{j}\right)=v-p_{j}-\frac{t}{4 n_{R}}+\frac{p_{j}-p_{i}}{n_{R}}+\frac{\left(p_{j}-p_{i}\right)^{2}}{2 t}
$$

This is the value that passengers may anticipate, according to their degree of foresight, $\delta$, when booking a ticket.

\section{$5 \quad$ Equilibrium analysis}

In this Section, we first analyze the second-stage equilibrium in which retailers and airlines choose their prices and quantities, respectively. Then, we consider the first-stage equilibrium

\footnotetext{
${ }^{11}$ Condition (15) is needed to ensure that an equilibrium in pure strategies with a fully covered market exists. Our results are also robust to the introduction of random outside options that make consumption of retail products at the airport optional. Details are available from the authors upon request.
} 
in which the airport chooses landing charges and the number of retail concessions.

\subsection{Second-stage equilibrium}

In this Subsection, we solve for the second-stage equilibrium, when retailers and airlines simultaneously choose their prices and quantities, respectively.

Retail market. Each retailer chooses its price to maximize its profits given in (16), where $C S(\cdot)$ is as in (17). Formally,

$$
\begin{aligned}
\max _{p_{i}} \pi_{i}\left(p_{i}, \boldsymbol{p}_{j}\right)= & p_{i}\left(\frac{1}{n_{R}}+\frac{p_{j}-p_{i}}{t}\right) \\
& \times\left[1-p_{A}+\delta\left(v-p_{j}-\frac{t}{4 n_{R}}+\frac{p_{j}-p_{i}}{n_{R}}+\frac{\left(p_{j}-p_{i}\right)^{2}}{2 t}\right)\right] .
\end{aligned}
$$

Then the following Proposition can be formulated.

Proposition 1. The optimal retail price is given by

$$
p_{R}\left(p_{A}\right)=\frac{t \delta\left(4+3 n_{R}\right)+4 \gamma n_{R}^{2}-\sqrt{16 t \delta n_{R}^{2}\left(t \delta-\gamma n_{R}\right)+\left[t \delta\left(4+3 n_{R}\right)+4 \gamma n_{R}^{2}\right]^{2}}}{8 \delta n_{R}^{2}},
$$

where $\gamma \equiv 1-p_{A}+v \delta$. When $\delta>0$, this optimal retail price is always below the Salop equilibrium price, i.e., $\left.p_{R}\left(p_{A}\right)\right|_{\delta>0}<\left.p_{R}\left(p_{A}\right)\right|_{\delta=0}=\frac{t}{n_{R}}$.

This Proposition characterizes the optimal retail price as a function of the airfare, $p_{A}$. In case of perfectly myopic consumers $(\delta=0),(19)$ reduces to $p_{R}=t / n_{R}$, the standard Salop symmetric equilibrium price. In this limiting case, there is no interaction between the airline and the retail markets: retail competition does not affect the demand for air travel, since passengers do not anticipate any surplus from retail activities. By contrast, when consumers are forward looking $(\delta>0)$, they set a lower price as compared to the myopic price to increase the number of travelers, which in turn affects positively their profits.

The results in the Proposition put us now in the position to justify our parametric restriction (15). Since $p_{R} \leqslant t / n_{R}$ and $n_{R} \geqslant 2$, the restriction ensures that consumers always enjoy a strictly positive surplus in the retail market (i.e., $C S\left(p_{R}\right)>0$ from $(17)$ ).

Airline market. Airlines compete by choosing simultaneously and non-cooperatively their quantities, denoted as $q_{k}$ for the generic $k$-th airline. ${ }^{12}$ In line with the literature, ae-

\footnotetext{
${ }^{12}$ Cournot behavior is often taken in the literature as a proxy for airline competition with limited capacity; see, for instance, Zhang and Zhang (2006) and Brueckner and Proost (2010).
} 
ronautical services are sold to airlines at a uniform per-passenger landing fee $\ell .^{13}$ All other costs are normalized to 0 without further loss of generality. Airline $k$ 's profits are $\pi_{k}=\left[p_{A}\left(q_{k}, Q_{-k}\right)-\ell\right] q_{k}$, where $Q_{-k}$ denotes the sum of quantities offered by the other $n_{A}-1$ firms. Inverting (14), we can write the maximization problem for airline $k$ as

$$
\max _{q_{k}} \pi_{k}=\left[1+\delta C S\left(p_{R}\right)-q_{k}-Q_{-k}-\ell\right] q_{k}
$$

where we suppress the vector notation in $C S(\cdot)$ due to the symmetry of equilibrium retail prices. Differentiating with respect to $q_{k}$ and exploiting symmetry at equilibrium, we obtain the equilibrium airline quantity

$$
q_{A}\left(p_{R}\right)=\frac{1-\ell+\delta C S\left(p_{R}\right)}{n_{A}+1} .
$$

This is a standard Cournot equilibrium quantity for a linear demand with $n_{A}$ firms and marginal cost equal to $\ell$, plus a term $\delta C S\left(p_{R}\right)$ that acts as a demand shifter and depends on the extent to which retail surplus is internalized by passengers when booking tickets.

Finally, the inverse demand function for flights is given by $p_{A}=1-n_{A} q_{A}\left(p_{R}\right)+\delta C S\left(p_{R}\right)$, where $C S\left(p_{R}\right)=v-p_{R}-\frac{t}{4 n_{R}}$ (which comes from (17) after applying symmetry). Using (21), we finally obtain the optimal airfare

$$
p_{A}\left(p_{R}\right)=\frac{n_{A} \ell+1}{n_{A}+1}+\delta \frac{v-p_{R}-\frac{t}{4 n_{R}}}{n_{A}+1} .
$$

As before, the first term is the standard equilibrium price in a Cournot model. The second term is the retail consumer surplus, weighted by the foresight parameter $\delta$. The higher are the expected surplus and the consumer' foresight, the greater is the outward shift of the demand curve and, therefore, the equilibrium price.

Properties of second-stage equilibrium. Using (19) and (22), it is possible to solve for the second-stage equilibrium airfare and retail price. As the resulting expressions are rather cumbersome and not needed for the analysis that follows, we do not present them here. ${ }^{14}$ Some useful comparative statics results are shown instead in the following Proposition.

Proposition 2. In the second-stage, the equilibrium retail price varies as follows with

\footnotetext{
${ }^{13}$ Landing fees depend in the real world on many factors, the most important being aircraft weight and capacity. A linear per-passenger landing fee is usually assumed in the literature to capture the idea of heavier and larger aircraft being charged higher landing fees (see, e.g. Zhang and Zhang, 2006; Czerny, 2006 and 2013; and Haskel et al., 2013).

${ }^{14}$ The explicit expressions can be found in the proof of Proposition 5.
} 
respect to the landing charge and the number of retailers:

$$
\left.\frac{\partial p_{R}}{\partial n_{R}}\right|_{\delta=0}<0 ;\left.\quad \frac{\partial p_{R}}{\partial n_{R}}\right|_{\delta>0} \lessgtr 0 ;\left.\quad \frac{\partial p_{R}}{\partial \ell}\right|_{\delta=0}=0 ;\left.\quad \frac{\partial p_{R}}{\partial \ell}\right|_{\delta>0}<0 .
$$

When passenger are myopic, the retail price is $t / n_{R}$ (as in the standard Salop model) and decreases with the number of competing retailers. This feature typically carries over also to the case of forward looking consumers, despite a countervailing force due to the market expansion effect when consumers anticipate retail surplus. It is only under particular circumstances that this intuitive result may be reversed. A necessary, but not sufficient, condition to obtain the counterintuitive result that the retail price increases with the number of retailers, is that $\delta$ is very large, and $n_{A}$ and $v$ are very small.

As for the landing fee, the retail price decreases with the landing fee for any $\delta>0$. An increase in $\ell$ causes directly an increase in the airfare and passengers reduce their demand both for services; then retailers try to counteract this effect by decreasing their prices.

\section{$5.2 \quad$ First-stage equilibrium}

In the first stage, the airport sets the landing fee and chooses the number of retailers allowed to operate in its terminals. Concessions are assumed to be awarded competitively, e.g., by means of a first-price auction, to many identical firms bidding non-cooperatively, so that the airport is able to fully extract retail profits. ${ }^{15}$ Then, the airport's profits are

$$
\Pi\left(\ell, n_{R}\right)=n_{A} q_{A}\left(\ell+p_{R}\right)
$$

where we assume no airport costs, so that landing fees can be interpreted as unit margins over positive and constant marginal cost, and $p_{R}$ and $q_{A}$ are given by (19) and (21). The first-order conditions are

$$
\begin{gathered}
\frac{\partial \Pi}{\partial \ell}=q_{A}\left(1+\frac{\partial p_{R}}{\partial \ell}\right)+\left(\frac{\partial q_{A}}{\partial \ell}+\frac{\partial q_{A}}{\partial p_{R}} \frac{\partial p_{R}}{\partial \ell}\right)\left(\ell+p_{R}\right), \\
\frac{\partial \Pi}{\partial n_{R}}=q_{A} \frac{\partial p_{R}}{\partial n_{R}}+\left(\frac{\partial q_{A}}{\partial n_{R}}+\frac{\partial q_{A}}{\partial p_{R}} \frac{\partial p_{R}}{\partial n_{R}}\right)\left(\ell+p_{R}\right),
\end{gathered}
$$

where $q_{A}=\frac{1+\delta\left(v-p_{R}-\frac{t}{4 n_{R}}\right)-\ell}{n_{A}+1}, \frac{\partial q_{A}}{\partial \ell}=-\frac{1}{n_{A}+1}, \frac{\partial q_{A}}{\partial p_{R}}=-\frac{\delta}{n_{A}+1}$, and $\frac{\partial q_{A}}{\partial n_{R}}=\frac{\delta t}{4\left(n_{A}+1\right) n_{R}^{2}}$, while $\frac{\partial p_{R}}{\partial \ell}$ and $\frac{\partial p_{R}}{\partial n_{R}}$ are as characterized in Proposition 2. The solution to this maximization problem is complex in general, as the Hessian matrix of the profit function is not negative semi-definite

\footnotetext{
${ }^{15}$ This hypothesis implies and takes to the extreme a profit-sharing contract between the airport and the concessionaires, in which the sharing rule leaves the retailer's incentives unaffected. A different sharing rule would scale down the airport's retail profits, with no qualitative effect on our results.
} 
everywhere. Still, we can go a considerable way by looking first at analytical solutions in some important limiting cases.

Perfectly myopic consumers $(\delta=0)$. In this case, there is no interaction between airport and commercial services, and the cross effects $\partial q_{A} / \partial p_{R}, \partial q_{A} / \partial n_{R}$, and $\partial p_{R} / \partial \ell$ all simplify to zero. The first-order conditions (24) and (25) reduce to

$$
\begin{gathered}
\frac{\partial \Pi}{\partial \ell}=1-2 \ell-\frac{t}{n_{R}}=0, \\
\frac{\partial \Pi}{\partial n_{R}}=-\frac{n_{A} t(1-\ell)}{\left(n_{A}+1\right) n_{R}^{2}} \leqslant 0 .
\end{gathered}
$$

From (14), it is immediate to see that $\ell$ cannot exceed 1 , given that $p_{A} \geqslant \ell$. Hence, (27) is non-positive and the airport chooses to award a number of concessions resulting in the maximum admissible concentration, which is $n_{R}=2$. An interior solution for $\ell$ is instead possible, depending on the value of $t$. This is formalized in the following Proposition.

Proposition 3. Let $\left.\ell^{*}\right|_{\delta=0}$ and $\left.n_{R}^{*}\right|_{\delta=0}$ be the equilibrium landing fee and number of retailers respectively, when consumers are perfectly myopic. Then

i) $\left.\ell^{*}\right|_{\delta=0}= \begin{cases}\frac{1-\frac{t}{2}}{2} & \text { if } t<2, \\ 0 & \text { if } t \geqslant 2,\end{cases}$

ii) $\left.n_{R}^{*}\right|_{\delta=0}=2$.

The airport chooses the lowest possible number of retailers and a landing charge strictly lower than $1 / 2$, the standard monopoly level in a model with linear demand and unit intercept. This result is easy to interpret. First, with perfectly myopic passengers, retail profits are maximized with fewer retailers, and this does not backfire as passengers do not foresee the resulting higher retail price when booking their flights. Second, the airport can exploit the complementarity between aeronautical and retail activities by reducing $\ell$, thereby attracting more passengers that will purchase a certain amount of retail goods at the terminals. If $t$ is sufficiently high (that is, the only two retailers are highly differentiated), the landing fee can even be set at 0: the airport prefers in this case to make no profits from airlines and extract as much as possible from the retail side. ${ }^{16}$

Almost myopic consumers $(\delta \rightarrow 0)$. We now investigate the effect on $\ell^{*}$ and $n_{R}^{*}$ of an infinitesimal increase from 0 of $\delta$. Our results are summarized in the following Proposition.

\footnotetext{
${ }^{16}$ Our interpretation of landing fees as unit margins over marginal cost, together with a non-negativity constraint on landing fees, prevents us from looking at the conditions under which the airport finds it optimal to set $\ell$ below cost. This, however, does not alter significantly our results. Indeed, with myopic consumers and a positive marginal cost equal to $c$ for the airport, the equilibrium number of retailers is always equal to 2 , while the landing fee is zero when $t>2(1+c)$ and equal to $\frac{1+c-\frac{t}{2}}{2}$ otherwise, being below cost if $t>2(1-c)$.
} 
Proposition 4. Let $\left.\ell^{*}\right|_{\delta \rightarrow 0}$ and $\left.n_{R}^{*}\right|_{\delta \rightarrow 0}$ be the equilibrium landing fee and number of retailers when $\delta$ is positive but infinitesimally small. Let also $t_{1} \equiv \frac{8(1+\delta v)}{4+5 \delta}$ and $t_{2} \equiv \frac{4 n_{A}(1+\delta v)}{\delta\left(3+8 n_{A}\right)}$. Then i) $\left.\ell^{*}\right|_{\delta \rightarrow 0} \cong \begin{cases}\frac{1-\frac{t}{n_{R}}}{2}+\frac{\delta}{2}\left(v-\frac{5 t}{4 n_{R}}\right) & \text { if } t \leqslant t_{1}, \\ 0 & \text { if } t>t_{1},\end{cases}$ ii) $\left.n_{R}^{*}\right|_{\delta \rightarrow 0} \cong \begin{cases}2 & \text { if } t<t_{2}, \\ \frac{5 \delta t n_{A}+\sqrt{\delta t n_{A}\left[25 \delta t n_{A}+48\left(n_{A}+1\right)(1+\delta v)\right]}}{4 n_{A}(1+\delta v)} & \text { if } t \geqslant t_{2} .\end{cases}$

These optimal choices are approximated values since they are obtained using the firstorder Taylor's expansions around $\delta=0$ of (24) and (25). In the limiting case $\delta=0$, these optimal choices become $\left.\ell^{*}\right|_{\delta=0}$ and $\left.n_{R}^{*}\right|_{\delta=0}$; this can be seen by substituting $\delta=0$ into $\left.\ell^{*}\right|_{\delta \rightarrow 0}$ and $\left.n_{R}^{*}\right|_{\delta \rightarrow 0}$ and noting that, when $\delta=0$, the threshold $t_{1}$ equals 2 while $t_{2}$ goes to infinity.

Proposition 4 illustrates that a very small degree of foresight can have a significant impact on the airport's choices. When $t$ is sufficiently small, there is little differentiation and possibly too strong competition among retailers, hence the airport chooses the most concentrated retail market structure. However, as the retail surplus is partly anticipated by passengers, there is an upward demand shift for flights that induces the airport to increase its landing fee above the myopic landing fee $\left(\left.\ell^{*}\right|_{\delta=0}\right)$. Hence, $\left.\ell^{*}\right|_{\delta \rightarrow 0}$ is strictly greater than $\left.\ell^{*}\right|_{\delta=0}$ and this fee can also be above the standard monopoly level. When instead $t$ is high enough, the airport sets the landing fee to 0 , as in Proposition 3, and derives no aeronautical profits. But, in order to attract more passengers, it boosts their expected retail surplus by awarding concessions to additional retailers, so that $n_{R}^{*}>2$. While this has a depressing effect on retail profits, the demand expansion effect of having additional passengers prevails.

Although we take the airline market structure as given, since it is not the main focus of our attention, we observe from Proposition 4 that $n_{A}$ does not have an impact on the landing fee with almost myopic consumers. Instead, the higher is $n_{A}$, the lower is $n_{R}$ (as long as $t \geqslant t_{2}$ ): consumer surplus is already boosted by intense competition among airlines and thus, ceteris paribus, there is a reduced incentive to award additional concessions.

Forward looking consumers $(\delta \gg 0)$. We can find full closed-form solutions when the foresight parameter $\delta$ is large enough. When instead $\delta$ is not so large, we can obtain analytical solutions only in implicit forms, and we resort to plots to illustrate that the solutions' features highlighted for very low and very large values of $\delta$ actually carry over also for intermediate values of $\delta$. We start by stating the following Proposition.

Proposition 5. Let $\left.\ell^{*}\right|_{\delta \geqslant \frac{4}{5}}$ and $\left.n_{R}^{*}\right|_{\delta \geqslant \frac{4}{5}}$ be the equilibrium landing fee and number of retailers respectively, when consumers are forward looking with $\delta \geqslant 4 / 5$. Then

i) $\left.\ell^{*}\right|_{\delta \geqslant \frac{4}{5}}=\frac{1}{2}(1+\delta v)$,

ii) $\left.n_{R}^{*}\right|_{\delta \geqslant \frac{4}{5}} \rightarrow \infty$. 


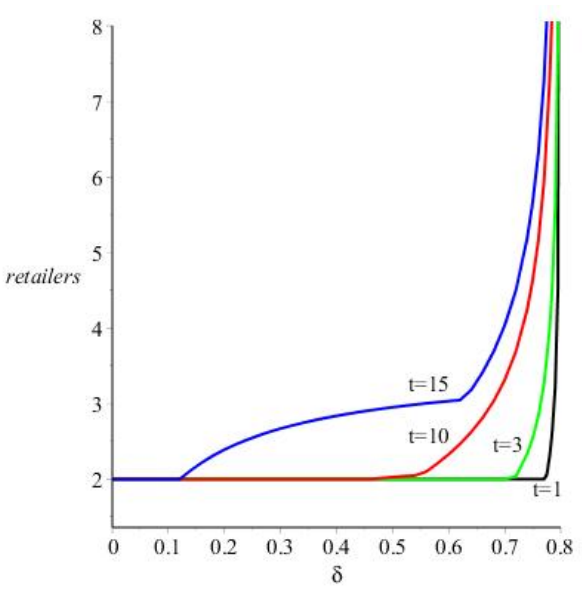

Panel A

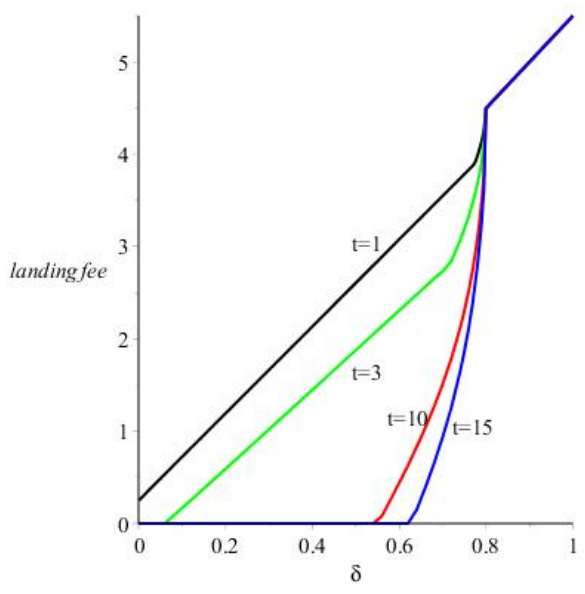

Panel B

Figure 1: Optimal number of retailers (panel A) and landing fee (panel B) for $t=1, t=3$, $t=10$, and $t=15$ (when $v=10$ and $n_{A}=5$ ).

The airport's optimal solution now changes completely. When $\delta$ is very large, the airport has an incentive to make the retail market as fragmented as possible, obtaining no rents, in order to increase the retail surplus. ${ }^{17}$ Retail surplus goes up not only because retail prices decrease down to marginal costs, but also because consumers find more product varieties, thus reducing transportation costs. This expected retail surplus pushes up considerably the demand for flights, and the airport can increase its profits by raising the landing fee.

To illustrate the optimal airport choices also for values of $\delta$ between 0 and $4 / 5$, for given combinations of the exogenous parameters $n_{A}$ and $v$, we plot the optimal values of $\ell$ and $n_{R}$ as a function of $\delta$ and $t$. These results are illustrated in Figure 1, together with those already presented in the Propositions of this Section. ${ }^{18}$ Panel A of Figure 1 plots the optimal number of retailers as a function of $\delta$, for different values of $t$. We observe that $n_{R}^{*}$ is always equal to 2 (i.e., its minimum value) when $\delta$ is sufficiently low, it then becomes an increasing function of $\delta$ for intermediate values of $\delta$, and it goes to infinity for $\delta \geqslant 4 / 5$, irrespective of $t$. For values of $\delta$ below $4 / 5$, the optimal number of retailers is always (weakly) monotonically increasing in $t$ : this implies that the airport is prepared to allow for less concentrated retailers as long as they do not compete too intensely.

The optimal landing fee is illustrated in Panel B of Figure 1, again as a function of $\delta$, and for different values of $t$. When $\delta>4 / 5$, the optimal landing fee, fully characterized in Proposition 5, is shown in the Figure to be identical for all values of $t$ and increasing in $\delta$. Below this threshold level of $\delta$, the optimal landing fee depends on $t$. In particular,

\footnotetext{
${ }^{17}$ The limiting result $n_{R}^{*} \rightarrow \infty$ comes from the assumption that there are no fixed (e.g., set up) costs for retail activities. If we allowed for some fixed costs, clearly $n_{R}^{*}$ would converge to some finite value.

${ }^{18}$ The plot analysis is primarily meant to illustrate the smoothness and monotonicity of our results for the range of $\delta$ for which we cannot derive explicit solutions.
} 
when $t$ is sufficiently low, $\ell^{*}$ is always strictly positive and strictly increasing with $\delta$ because retail competition is very strong even if the airport awards the minimum possible number of concessions. Thus, the airport cannot extract high rents from the retail side and relies mostly on aeronautical services via sufficiently high landing fees. Instead, for higher values of $t$, the relative importance of the two sources of revenues is reversed and we can even observe $\ell^{*}=0$ when $\delta$ is intermediate (and then it becomes increasing in $\delta$ ). Retail competition is now not very intense and high rents can be extracted from the retail sector. The airport can therefore afford making little (even 0) money from the aeronautical sector and concentrate on the optimal retail structure, which can include more than 2 retailers when this boosts the ex ante demand for air travel. For the entire range of $\delta$, the optimal landing fee is (weakly) monotonically decreasing in $t$. We note again that the landing fee can, in many instances, be set above $1 / 2$ (the standard monopoly level), in particular when $\delta$ is large or when $t$ is small. ${ }^{19}$

\subsection{Airport's profits and managerial implications}

We discuss how the airport's profits vary with consumer foresight, which yields some clear managerial implications. We not only look at the relationship between $\delta$ and the airport's aggregate profits, but also distinguish between the effect of $\delta$ on the relative profits from retail and aeronautical activities.

Proposition 6. Let $\pi^{*}, \pi_{R}^{*}$, and $\pi_{A}^{*}$ be the airport's equilibrium profits from all, retail, and aeronautical activities, respectively, with $\pi^{*}=\pi_{R}^{*}+\pi_{A}^{*}$. Let also $v_{1} \equiv \frac{t\left(9 t n_{A}+10 n_{A}+4 t\right)}{8 n_{A}(t+2)}$ and $v_{2} \equiv \frac{t\left(7 n_{A}+2\right)}{8 n_{A}}$. Then

i) Aggregate profits: $\pi^{*}$ is highest when $\delta=1$. Also, $\left.\frac{\partial \pi^{*}}{\partial \delta}\right|_{\delta=0}>0$ if and only if $v>v_{1}$ when $t<2$ and $v>v_{2}$ when $t \geqslant 2$;

ii) Retail profits: $\left.\pi_{R}^{*}\right|_{\delta=0}>0$ and $\left.\pi_{R}^{*}\right|_{\delta \geq \frac{4}{5}}=0$. Also, $\left.\frac{\partial \pi_{R}^{*}}{\partial \delta}\right|_{\delta=0}>0$ if and only if $v>v_{2}$; iii) Aeronautical profits: $\left.\pi_{A}^{*}\right|_{\delta=0}>0$ if and only if $t<2$. Also, $\left.\frac{\partial \pi_{A}^{*}}{\partial \delta}\right|_{\delta=0} \geqslant 0$ for any $v$.

The Proposition shows that the airport's total profits (almost) always increase with the degree of consumer foresight, as illustrated by the solid lines in Figure 2 (drawn using the same parameter values as in Figure 1). ${ }^{20}$ Consumer foresight has two direct effects on the airport's profits. First, it increases the retail profits, which are fully extracted by

\footnotetext{
${ }^{19}$ Our results can be reinterpreted along the lines of the literature on two-part tariffs and, in particular, with reference to Oi's (1971) classic study of a Disneyland monopolist. We obtain a result similar to Oi's in which secondary goods are priced at marginal cost, only when passengers are sufficiently forward-looking. In this case, the number of retailers goes to infinity, the retail prices approach their marginal cost (0 in our model), and transportation costs go to 0 , so that ex post consumer surplus is maximized. However, this result breaks down completely as consumers exhibit a certain degree of myopia.

${ }^{20}$ A similar result is found in Hagiu and Halaburda (2014).
} 
the airport. This is because it gives the retailers an instrument to increase the number of passengers/customers. Indeed, when consumers anticipate the benefit from the retail market when buying the flight tickets, the optimal retail price is lower than in the case of myopic consumers. This lower price increases the number of travelers (and thus the number of retail customers), which generates larger retail profits. Second, consumer foresight increases the demand in the airline market, which yields larger airlines' profits that are (partly) appropriated by the airport by means of the landing fee. When consumers are foresighted, their willingness to pay for flights increases. Hence, demand shifts outwards and the equilibrium price (and airlines' profit) increases. This allows the airport to use the landing fee to extract airlines profits, which are now larger than in the case of myopic consumers. Thus, foresight gives the airport not only a richer set of instruments to pursue its profit-maximizing objectives, but also a larger amount of total profits (as generated in the airline and retail markets) to appropriate.

The effects described above and the optimal combinations of landing fee and number of retailers chosen by the airport change the relative profitability of the different components of its business. These results are also illustrated in Figure 2, where retail and aeronautical profits are illustrated by a dashed and a dotted line, respectively.

Looking at the evolution of aeronautical profits, at $\delta=0$, the airport only makes money from the aeronautical business when landing fee is set above cost only when $t<2$, as formalized in Proposition 3 (Panel A). Elsewhere, the landing fee is set equal to cost and the airport makes no money from the aeronautical business (Panels B-C-D). For higher values of $\delta$, aeronautical profits are zero when consumers are sufficiently myopic and $t$ is large enough, while, in all other cases, they are positive and increase with $\delta$. Retail profits are positive when consumers are perfectly myopic since the airport chooses the most concentrated retail market, whereas they are equal to zero when $\delta$ is sufficiently high since the airport prefers the most dispersed retail market (Panels A-B-C-D). The highest aggregate profits are attained when $\delta$ is equal 1, i.e., when consumers have perfect foresight (Panels A-B-C-D). Although, it can be observed that they typically increase with $\delta$, this is not a general result. For $\delta$ around 0 , profits may locally decrease as $\delta$ goes up when $t$ is sufficiently large relatively to the other model's parameters (or, equivalently, when $v$ is sufficiently small), as illustrated in Panel D. ${ }^{21}$

Notice finally that the shares of profits derived from retail and aeronautical activities change with $\delta$ and also with $t$. More precisely, $t$ plays a role in determining the relevance of the two sources of profits only when $\delta$ is small or moderate. To see this, start with

\footnotetext{
${ }^{21}$ This result depends on the nature of the retail market. When $t$ is small (or, equivalently, when $v$ is large), a small increase in $\delta$ from 0 has a positive effect on retail profits (see Panels A-B-C). Instead, when $t$ is large, a local increase in $\delta$ from 0 reduces the airport retail profits (see Panel D).
} 


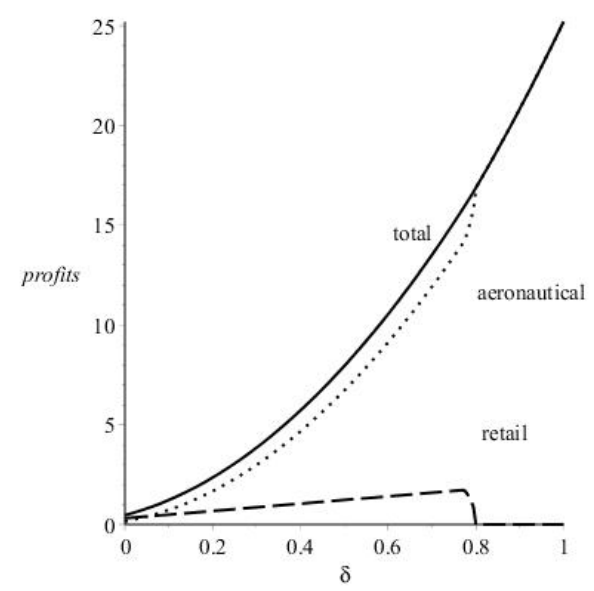

Panel A: $t=1$

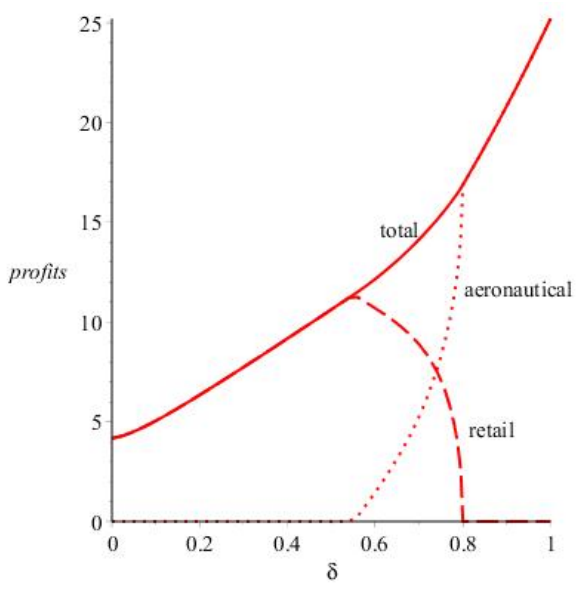

Panel C: $t=10$

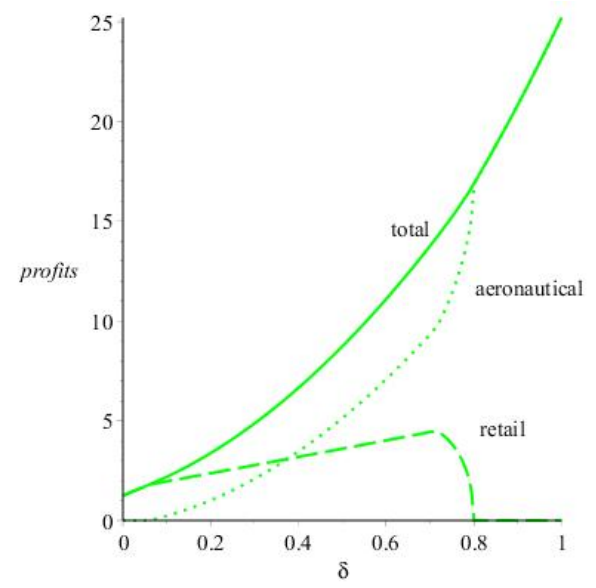

Panel B: $t=3$

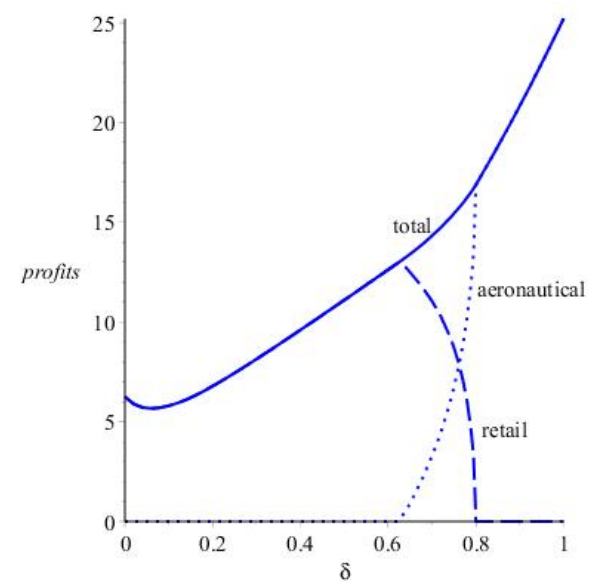

Panel D: $t=15$

Figure 2: Equilibrium profits (when $v=10$ and $n_{A}=5$ ).

small or moderate values of $\delta$. In Panel $\mathrm{A}$, for instance, there is little differentiation among retailers: the retail sector is concentrated, aeronautical profits are always positive for any $\delta$ (the landing fee is always positive) and generally represent the biggest share of total profits. Moving to Panels B-C-D, as retail differentiation increases, the airport awards more concessions and we observe an increased importance of retail profits relative to aeronautical profits for intermediate values of $\delta$. Finally, as illustrated in Proposition 5, when $\delta \geqslant 4 / 5$ the retail sector is always maximally fragmented, no profits are made from retail activities and $t$ is therefore irrelevant for the level of total profits.

Our results have some interesting implications for managers of an airport platform. In particular, they inform managers on how to think about revenues from a primary good (aeronautical services) and a second complementary good (retail services), when this secondary good may be more or less salient in the consumers' initial choice, according to 
their degree of foresight. Given the optimal policies described in Section 5.2 and the evolution of profits shown above in this section, a larger degree of consumer foresight has, in most cases, a positive effect on aeronautical profits and a negative effect on retail profits. When consumers are sufficiently myopic, the airport optimally charges a low landing fee to attract consumers to the airport and derives most of its profits from the retail activities by choosing a concentrated retail market. As $\delta$ becomes larger, the retail market becomes a better instrument to induce consumers to purchase a flight ticket: the number of concessions awarded increases and consumers appropriate a larger share of the surplus created in the retail activities. This leads to an increase in passengers, which benefits the airport as it can charge higher landing fees and derive most, if not all, of its profits from the aeronautical side alone.

A limit of our analysis is that the degree of consumer foresight is assumed to be exogenous. We note, however, that it could be affected by the airport, for instance with appropriate informative campaigns, as it is often observed now in several airports. ${ }^{22}$ Actually, the fact that airports do advertise their retail facilities is already an indication that, in practice, $\delta$ cannot be zero, as otherwise there would be no reason to inform (or manipulate information) about something that does not affect traveling demand in case consumers were fully myopic. ${ }^{23}$ Hence our results on the relationship between the airport profits and the degree of consumer foresight could not only inform managers on the most appropriate airport's choices on landing fees and retail market structure, but also determine their incentives to engage in advertising campaigns on the retail activities available at the airport.

As profits may locally decrease as $\delta$ goes up (for $\delta$ around 0 ), small informative campaigns may be counterproductive when the consumer foresight is very low and the retail market is able to generate little profits because of the low consumers' willingness to spend. Yet, more ambitious (and costly) informative campaigns may actually be very profitable. Of course, since we do not model the cost side of advertising campaigns and how they relate to consumer foresight, we do not seek to characterize the optimal level of informative advertising. ${ }^{24}$ We do however stress that it might be in the airport's interest to increase the degree of awareness of travelers about their retail experience while at the airport.

\footnotetext{
${ }^{22}$ In other non-airport settings, we often observe the symmetric problem of firms having to strategically determine the extent to which they should shroud the product/add-on attributes or prices: see, e.g., Gabaix and Laibson (2006) and Wenzel (2014).

${ }^{23}$ For instance, on the website of Dubai airport, you may read: "Dubai is a shopper's paradise. And so is our airport. From local delicacies to luxury brands, travel essentials to tempting indulgences, we offer something for everyone" (www.dubaiairports.ae). Also, think of the iconic shopping slogan "See Buy Fly" created by Amsterdam Schipol Airport, one of Europe's largest hubs; see www.schiphol.nl.

${ }^{24} \mathrm{An}$ interior solution to this optimal level of advertising could be granted by an increasing and sufficiently convex advertising cost, and would be dependent on the cost function parameters.
} 


\section{Concluding remarks and policy implications}

Revenue at airports comes from two sources: aeronautical and retail activities. When airports earn over $50 \%$ of their revenues from retailing, there is a need to understand the implications of consumer behavior for airports' business models. This paper provides a novel framework to think about this problem. We argue that the relative importance of these sources depends on the degree of consumer foresight about the ex post retail surplus when purchasing a flight ticket. We identify a clear trade-off between the retail market structure and the landing fee, depending on the degree of consumer foresight. When consumers are myopic, the airport awards very few retail concessions that turn out to be very lucrative, while landing fees are kept low to lure passengers in the airport terminal. As consumer foresight increases, the optimal retail structure becomes more fragmented while the landing fee increases, until the airport chooses to earn money only from aeronautical services.

While airports represent the motivation for our analysis, we argued that our model of platform pricing could be applied (with suitable adaptations) to other settings where an intermediary offers a primary and a secondary good. We provided, for instance, the examples of shopping malls and of video game consoles. Indeed, the general model we investigate shows that the main results of our analysis carry over to a more general, not airport-specific, platform setting where the questions of consumer foresight and (secondary good) market structure are present.

Although the analysis undertaken in this paper adopts a strictly positive perspective, some normative implications can be directly derived. Given that there are no set-up costs associated to retail activities and airlines compete imperfectly (in the absence of congestion), the first-best solution would require the most fragmented market structure on the retail side and the lowest possible landing fee (equal to zero) on the aeronautical side to minimize the effect of airlines' market power. In addition, a more thorough first-best analysis would require to take a stance with respect to the socially optimal degree of consumer foresight, a matter that is difficult to ascertain from first principles.

Therefore, comparing private and public incentives, we conclude that, as consumers' foresight increases, the airport moves towards a socially-optimal fragmented market structure on the retail side, but this occurs at the expense of an inefficiently high landing fee. Conversely, higher values of consumers' myopia are associated with a more efficient landing fee together with an inefficiently concentrated market structure in the retail sector.

Although we have dealt with an unregulated platform, some regulatory implications can be derived from our results. With perfectly myopic consumers, our model provides some support for the recent airport claims in favor of a deregulation of charges on the basis of the two-sided nature of the airport business (Charles River Associates, 2013). This is because 
the airport's incentive to reduce the landing fee is well aligned with the one of a benevolent regulator with the same degree of myopia. However, when consumers are forward looking, the landing fee may even exceed the monopoly price and, therefore, airport regulation of landing fees may be socially beneficial. This is just an example of how our platform approach can help analyzing the many regulatory questions still outstanding, such as single vs. dual till regulation, and that we hope future research will address.

\section{References}

ACI, 2012. ACI airport economics survey 2012.

Armstrong, M., 2006. Competition in two-sided markets. Rand Journal of Economics 37 (3), 669-691.

ATRS, 2014. Global airport benchmarking report 2014.

Boudreau, K., 2010. Open platform strategies and innovation: Granting access vs. devolving control. Management Science 56 (10), 1849-1872.

Brueckner, J. K., 1993. Inter-store externalities and space allocation in shopping centers. Journal of Real Estate Finance and Economics 7 (1), 5-16.

Brueckner, J. K. and S. Proost, 2010. Carve-outs under airline antitrust immunity. International Journal of Industrial Organization 28 (6), 657-668.

Busse, M. R., C. R. Knittel and F. Zettelmeyer, 2013. Are consumers myopic? Evidence from new and used car purchases. American Economic Review 103 (1), 220-256.

Caillaud, B. and B. Jullien, 2003. Chicken and egg: Competition among intermediation service providers. Rand Journal of Economics 34 (2), 309-328.

Carter, C. C., 2009. What we know about shopping centers. Journal of Real Estate Literature 17 (2), 165-180.

Carter, C. C. and K. D. Vandelland, 2006. Store location in shopping centers: Theory and estimates. Journal of Real Estate Research 27 (3), 237-265.

Charles River Associates, 2013. Two sided market analysis in the context of the CAA's market power analysis - report for the CAA.

Chetty, R., 2015. Behavioral economics and public policy: A pragmatic perspective. American Economic Review: Papers and Proceedings 105 (5), 1-33.

Czerny, A. I., 2006. Price cap regulation of airports: Single till versus dual till. Journal of Regulatory Economics 30 (1), 85-97.

Czerny, A. I., 2013. Public versus private airport behavior when concession revenues exist. Economics of Transportation 2 (1), 38-46.

Czerny, A. I. and R. Lindsey, 2014. Multiproduct pricing with core goods and side goods. Discussion Paper No. 14-03, German Economic Association of Business Administration.

Ellison, G., 2005. A model of add-on pricing. Quarterly Journal of Economics 120 (2), 585-637.

Gabaix, X. and D. Laibson, 2006. Shrouded attributes and information suppression in competitive markets. Quarterly Journal of Economics 121 (2), 505-540. 
Gale, I. and D. P. O'Brien, 2013. The welfare effects of use-or-lose provisions in markets with dominant firms. American Economic Journal: Microeconomics 5 (1), 175-193.

Gans, J. S. and S. P. King, 2000. Mobile network competition, customer ignorance and fixed-tomobile call prices. Information Economics and Policy 12 (4), 301-327.

Gillen, D. and B. Mantin, 2012. Transportation infrastructure management: One and two sided market approaches. Journal of Transport Economics and Policy 47 (2), 207-227.

Hagiu, A., 2009. Two-sided platforms: Product variety and pricing structures. Journal of Economics \& Management Strategy 18 (4), 1011-1043.

Hagiu, A. and H. Halaburda, 2014. Information and two-sided platform profits. International Journal of Industrial Organization 34, 25-35.

Hagiu, A. and D. Spulber, 2013. First-party content and coordination in two-sided markets. Management Science 59 (4), 933-949.

Haskel, J., A. Iozzi and T. Valletti, 2013. Market structure, countervailing power and price discrimination: The case of airports. Journal of Urban Economics 74 (1), 12-26.

Heidhues, P. and B. Köszegi, 2010. Exploiting naivete about self-control in the credit market. American Economic Review 100 (5), 2279-2303.

Ivaldi, M., S. Sokullu and T. Toru, 2015. Airport prices in a two-sided market setting: Major US airports. Mimeo.

Karle, H. and M. Peitz, 2014. Competition under consumer loss aversion. Rand Journal of Economics 45 (1), 1-31.

Lal, R. and C. Matutes, 1994. Retail pricing and advertising strategies. Journal of Business 67 (3), 345-370.

Miceli, T. J. and C. F. Sirmans, 1995. Contracting with spatial externalities and agency problems: The case of shopping center leases. Regional Science and Urban Economics 25 (3), 355-372.

Mintel, 2013. Airport retailing - Europe, March 2013.

Nocke, V., M. Peitz and K. Stahl, 2007. Platform ownership. Journal of the European Economic Association 5 (6), 1130-1160.

Oi, W. Y., 1971. A Disneyland dilemma: Two-part tariffs for a Mickey Mouse monopoly. Quarterly Journal of Economics 85 (1), 77-96.

Rochet, J.-C. and J. Tirole, 2003. Platform competition in two-sided markets. Journal of the European Economic Association 1 (4), 990-1029.

Starkie, D., 2001. Reforming UK airport regulation. Journal of Transport Economics and Policy 35 (1), 119-135.

The Economist, 2014. Airport shopping: The sixth continent. 20 May.

Van Dender, K., 2007. Determinants of fares and operating revenues at US airports. Journal of Urban Economics 62 (2), 317-336.

Wenzel, T., 2014. Consumer myopia, competition and the incentives to unshroud add-on information. Journal of Economic Behavior and Organization 98, 89-96.

Wright, J., 2004. One-sided logic in two-sided markets. Review of Network Economics 3 (1), 44-64.

Zhang, A. and Y. Zhang, 1997. Concession revenue and optimal airport pricing. Transportation Research Part E 33 (4), 287-296. 
Zhang, A. and Y. Zhang, 2006. Airport capacity and congestion when carriers have market power. Journal of Urban Economics 60 (2), 229-247.

\section{Appendix A: Proofs}

In this Appendix, we provide the proofs of all Propositions of Sections 4 and 5.

Proof of Proposition 1. First, notice that the value of the expected surplus when one retailer charges $p_{i}$ and all other retailers charge symmetrically $p_{j}$ can be expressed as follows

$$
\begin{aligned}
C S\left(p_{i}, \boldsymbol{p}_{j}\right)= & 2 \int_{0}^{\widetilde{x}_{i j}}\left(v-p_{i}-t x\right) d x+2 \int_{\widetilde{x}_{i j}}^{\frac{1}{n_{R}}}\left[v-p_{j}-t\left(\frac{1}{n_{R}}-x\right)\right] d x \\
& +\frac{n_{R}-2}{n_{R}}\left(v-p_{j}-\frac{t}{4 n_{R}}\right) .
\end{aligned}
$$

The first term is the expected value of the consumer's utility when she ends up being located on the right-side (clockwise) of firm $i$ and purchases from it; this is multiplied by 2 to include the same expectation on the left-side of firm $i$. The second term is the expected value of the consumer's utility when she purchases from the first retailer $j$ on the right of firm $i$ (hence at a distance $\frac{1}{n_{R}}-x$ away from $j$ ); this is again multiplied by 2 for the same argument. The last term represents the expected utility from purchasing with the remaining $n_{R}-2$ symmetric firms. Using the definition of the marginal consumer and evaluating the integral, the expected retail consumer surplus in (A-1) gives 17.

Turing now to retailer $i$ 's problem, imposing symmetry (i.e., $p_{i}=p_{j}=p_{R}$ ), the firstorder condition of its problem (18) is

$$
\frac{\partial \pi_{i}}{\partial p_{i}}=\frac{t n_{R}\left[4\left(1-p_{A}+\delta v\right)-3 \delta p_{R}\right]-4 n_{R}^{2} p_{R}\left(1-p_{A}-\delta p_{R}+\delta v\right)-t\left(4 p_{R}+t\right)}{4 t n_{R}^{2}}=0
$$

First, we establish the optimal retail price in (19). Solving (A-2) with respect to $p_{R}$ and using $\gamma$, we obtain two solutions

$$
p_{R}^{\prime}, p_{R}^{\prime \prime}=\frac{\delta t\left(4+3 n_{R}\right)+4 \gamma n_{R}^{2} \pm \sqrt{16 \delta t n_{R}^{2}\left(\delta t-\gamma n_{R}\right)+\left[\delta t\left(4+3 n_{R}\right)+4 \gamma n_{R}^{2}\right]^{2}}}{8 \delta n_{R}^{2}} .
$$

To select the correct solution, first rewrite the first-order condition (A-2) as follows

$$
\underbrace{4 \delta n_{R}^{2} p_{R}^{2}}_{Q\left(p_{R}\right)}=\underbrace{-\delta t\left(4 v n_{R}-t\right)-4 t n_{R}\left(1-p_{A}\right)+\left[4 n_{R}^{2}\left(1-p_{A}\right)+4 \delta t+3 \delta t n_{R}+4 \delta v n_{R}^{2}\right] p_{R}}_{L\left(p_{R}\right)} .
$$




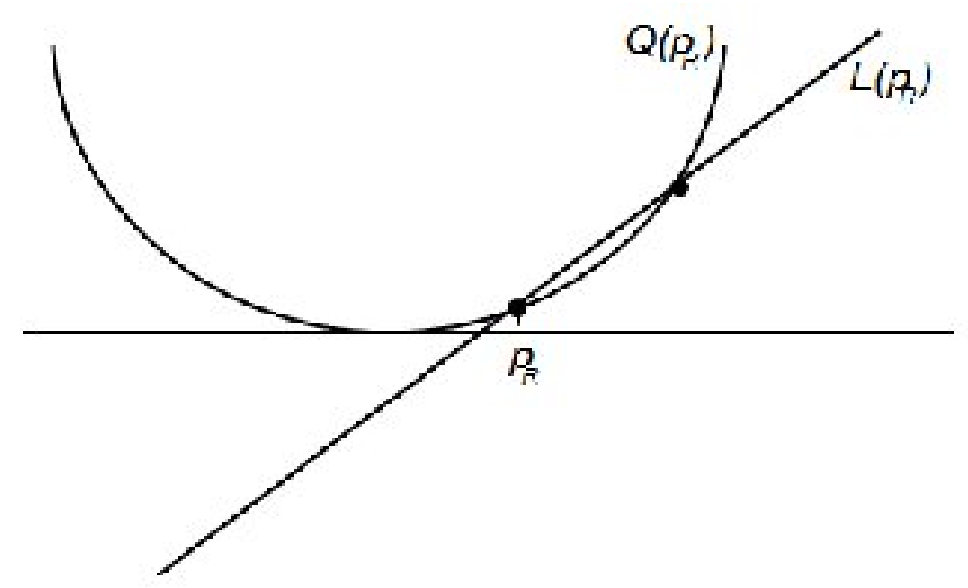

Figure A-1: The first-order condition of retailer $i$ 's maximization problem

Figure A-1 illustrates that (A-4) is satisfied at the intersection between two functions of $p_{R}$, one quadratic, $Q\left(p_{R}\right)$, and one linear, $L\left(p_{R}\right)$. Note that $L\left(p_{R}\right)$ has a negative intercept and that it is necessarily upward sloping. Notice also that, at the smallest solution in Figure $\mathrm{A}-1, \frac{\partial Q\left(p_{R}\right)}{\partial p_{R}}<\frac{\partial L\left(p_{R}\right)}{\partial p_{R}}$, while at the largest solution in Figure A-1, $\frac{\partial Q\left(p_{R}\right)}{\partial p_{R}}>\frac{\partial L\left(p_{R}\right)}{\partial p_{R}}$.

The second-order condition of problem (18) is given by

$$
\delta n_{R}\left(6 p_{R}+t\right)-4 n_{R}^{2}\left(1-p_{A}-\delta p_{R}+\delta v\right)-4 \delta t<0,
$$

which can be rewritten as

$$
\frac{\partial L\left(p_{R}\right)}{\partial p_{R}}-\frac{\partial Q\left(p_{R}\right)}{\partial p_{R}}>2 \delta n_{R}\left[2\left(t-n_{R} p_{R}\right)+3 p_{R}\right]
$$

where

$$
\frac{\partial L\left(p_{R}\right)}{\partial p_{R}}=-\delta t\left(4 v n_{R}-t\right)-4 t n_{R}\left(1-p_{A}\right)+\left[4 n_{R}^{2}\left(1-p_{A}\right)+4 \delta t+3 \delta t n_{R}+4 \delta v n_{R}^{2}\right]
$$

and

$$
\frac{\partial Q\left(p_{R}\right)}{\partial p_{R}}=-8 \delta n_{R}^{2} p_{R}
$$

Noting that the right-hand side of (A-6) satisfies $2 \delta n_{R}\left[2\left(t-n_{R} p_{R}\right)+3 p_{R}\right]>0$ because $p_{R}<\frac{t}{n_{R}}$ as long as $\delta>0$, one can conclude that, for (A-6) to be satisfied, $\frac{\partial L\left(p_{R}\right)}{\partial p_{R}}-\frac{\partial Q\left(p_{R}\right)}{\partial p_{R}}>0$ must hold, which establishes that the smallest solution in Figure A-1 is the unique solution to the maximization problem (18).

We now turn to prove the inequality in the last part of the Proposition. First, note that (A-2) evaluated at $\delta=0$ yields $\left.\frac{\partial \pi_{i}}{\partial p_{i}}\right|_{\delta=0}=\frac{\left(1-p_{A}\right)\left(t-n_{R} p_{R}\right)}{n_{R} t}=0$. Solving with respect to $p_{R}$ gives $\left.p_{R}\left(p_{A}\right)\right|_{\delta=0}=\frac{t}{n_{R}}$, which is the standard price in a Salop model. Using $\left.p_{R}\left(p_{A}\right)\right|_{\delta=0}=\frac{t}{n_{R}}$ 
into (A-2) yields $-\frac{t \delta}{n_{R}^{3}}<0$, i.e., the first-order condition is always negative at the Salop price. Therefore, $\left.p_{R}\left(p_{A}\right)\right|_{\delta>0}$ will take a smaller value than $\frac{t}{n_{R}}$ for any $\delta>0$.

Proof of Proposition 2. Substituting the equilibrium airfare in (22) into the retail price first-order condition in (A-2), we obtain

$$
\begin{aligned}
\Omega \equiv & \frac{n_{A}\left\{t n_{R}\left[4(1-\ell)-\delta\left(3 p_{R}+4 v\right)\right]-4 n_{R}^{2} p_{R}\left(1-\delta p_{R}+\delta v-\ell\right)-\delta t\left(4 p_{R}+t\right)\right\}}{4 t n_{R}^{2}\left(n_{A}+1\right)} \\
& -\frac{\delta p_{R}}{n_{R}^{2}\left(n_{A}+1\right)}=0 .
\end{aligned}
$$

Implicitly differentiating it, we obtain

$$
\begin{aligned}
\frac{\partial p_{R}}{\partial \ell} & =-\frac{\partial \Omega / \partial \ell}{\partial \Omega / \partial p_{R}}=\frac{4 n_{A} n_{R}\left(t-n_{R} p_{R}\right)}{-n_{A}\left[4 n_{R}^{2}\left(1-2 \delta p_{R}+\delta v-\ell\right)+3 \delta t n_{R}+4 \delta t\right]-4 \delta t}, \\
\frac{\partial p_{R}}{\partial n_{R}} & =-\frac{\partial \Omega / \partial n_{R}}{\partial \Omega / \partial p_{R}}=\frac{t\left\{-2 n_{A}\left[\delta\left(t-2 v n_{R}\right)-2 n_{R}(1-\ell)\right]-\delta p_{R}\left[3 n_{A} n_{R}+8\left(n_{A}+1\right)\right]\right\}}{n_{R}\left\{-n_{A}\left[4 n_{R}^{2}\left(1-2 \delta p_{R}+\delta v-\ell\right)+3 \delta t n_{R}+4 \delta t\right]-4 \delta t\right\}} .
\end{aligned}
$$

As to (A-10), the numerator is positive since Proposition 1 establishes that $p_{R}<\frac{t}{n_{R}}$ when $\delta>0$. The denominator is negative because it is smaller than the second-order condition in (A-5), which is negative after replacing the equilibrium airfare in (22).

As to (A-11), the denominator is again negative as in (A-5). The numerator is decreasing in $p_{R}$, hence it takes a lower bound at $p_{R}=\frac{t}{n_{R}}$, in which case the numerator simplifies to

$$
-\frac{t}{n_{R}}\left\{8 t \delta+n_{A}\left[8 t \delta+5 n_{R} t \delta-4 n_{R}^{2}(1-\ell+v \delta)\right]\right\}
$$

When this last expression is positive, then (A-11) is negative overall. From (A-12), a sufficient condition is therefore that

$$
v>-\frac{1-\ell}{\delta}+\frac{5 t}{4 n_{R}}+\frac{2\left(1+n_{A}\right) t}{n_{A} n_{R}^{2}}
$$

This condition is always satisfied when $\delta$ is low enough. From (15), recall also that $v>\frac{5 t}{8}$, which ensures that $v$ is always greater than the second term on the RHS of (A-13). Hence we expect that $\frac{\partial p_{R}}{\partial n_{R}}<0$ in most cases. However, the third term of the RHS of (A-13) is a countervailing effect that may change the sign of $\frac{\partial p_{R}}{\partial n_{R}}$ : a necessary (but still not sufficient) condition for $\frac{\partial p_{R}}{\partial n_{R}}$ to be positive overall is that $\delta$ is large, $n_{A}$ is small, and $v$ is also small.

Proof of Proposition 3. Directly in the text and therefore omitted.

Proof of Proposition 4. Substituting the values of $q_{A}, \frac{\partial q_{A}}{\partial \ell}, \frac{\partial q_{A}}{\partial p_{R}}, \frac{\partial q_{A}}{\partial n_{R}}, \frac{\partial p_{R}}{\partial \ell}$, and $\frac{\partial p_{R}}{\partial n_{R}}$ into 
(24) and (25), we obtain

$$
\begin{aligned}
\frac{\partial \Pi}{\partial \ell} & =\underbrace{\left(1-2 \ell-\frac{t}{n_{R}}\right)}_{A}+\underbrace{4 n_{R} n_{A}\left(n_{R} p_{R}-t\right) \Upsilon}_{B}+\underbrace{\left[\frac{t(4-\delta)}{4 n_{R}}+\delta v-p_{R}(1+\delta)\right]}_{B}=0, \\
\frac{\partial \Pi}{\partial n_{R}} & =\underbrace{-\frac{t n_{A}(1-\ell)}{\left(n_{A}+1\right) n_{R}^{2}}}_{D}+\underbrace{\frac{t n_{A}}{\left(n_{A}+1\right) n_{R}} \Psi=0,}_{E}
\end{aligned}
$$

with $\Upsilon \equiv \frac{1-\ell+\delta\left(v-2 p_{R}-\ell-\frac{t}{4 n_{R}}\right)}{n_{A}\left[4 n_{R}^{2}\left(1-2 \delta p_{R}+\delta v-\ell\right)+3 \delta t n_{R}+4 \delta t\right]+4 \delta t}$ and $\Psi \equiv \frac{4(1-\ell)+\delta\left(\ell+p_{R}\right)}{4 n_{R}}+\Upsilon\left\{8 \delta p_{R}+n_{A}\left[2 \delta\left(4 p_{R}+t\right)\right.\right.$ $\left.\left.-n_{R}\left(4-3 \delta p_{R}+4 \delta v-4 \ell\right)\right]\right\}$.

From (26) and (27), we have that $A=\left.\frac{\partial \Pi}{\partial \ell}\right|_{\delta=0}$ and $D=\left.\frac{\partial \Pi}{\partial n_{R}}\right|_{\delta=0}$. Notice also that both $A$ and $D$ do not depend on $\delta$, so that $\frac{\partial A}{\partial \delta}=\frac{\partial D}{\partial \delta}=0$. Also, we observe that $\left.\frac{\partial B}{\partial \delta}\right|_{\delta \rightarrow 0}=0$, given that, for $\delta=0, p_{R}=\frac{t}{n_{R}}$ and the denominator of $B$ takes on a strictly positive value. Hence, $\left.\frac{\partial^{2} \Pi}{\partial \ell \partial \delta}\right|_{\delta=0}=\left.\frac{\partial C}{\partial \delta}\right|_{\delta=0}$ and $\left.\frac{\partial^{2} \Pi}{\partial n_{R} \partial \delta}\right|_{\delta=0}=\left.\frac{\partial E}{\partial \delta}\right|_{\delta=0}$.

Since our analysis is limited to $\delta$ infinitesimally close to 0 , it is legitimate to approximate the first-order conditions by their first order Taylor's expansions. Hence, (A-14) and (A-15) become

$$
\begin{aligned}
\frac{\partial \Pi}{\partial \ell} & \left.\cong \frac{\partial \Pi}{\partial \ell}\right|_{\delta=0}+\left.\delta \frac{\partial^{2} \Pi}{\partial \ell \partial \delta}\right|_{\delta=0}=A+\left.\delta \frac{\partial C}{\partial \delta}\right|_{\delta=0} \\
& =1-2 \ell-\frac{t}{n_{R}}+\delta\left(v-\frac{5 t}{4 n_{R}}\right)=0, \\
\frac{\partial \Pi}{\partial n_{R}} & \left.\cong \frac{\partial \Pi}{\partial n_{R}}\right|_{\delta=0}+\left.\delta \frac{\partial^{2} \Pi}{\partial n_{R} \partial \delta}\right|_{\delta=0}=D+\left.\delta \frac{\partial E}{\partial \delta}\right|_{\delta=0} \\
& =\frac{1}{n_{R}^{2}}\left\{-\frac{t n_{A}(1-\ell)}{\left(n_{A}+1\right)}+\delta t \frac{n_{A}\left[n_{R}^{2}(5 \ell-4 v)+2 t\left(5 n_{R}+6\right)\right]+12 t}{4 n_{R}^{2}\left(n_{A}+1\right)}\right\}=0 .
\end{aligned}
$$

It is then immediate to see that (A-16) is negative when $t>t_{1}$. When instead $t \leqslant t_{1}$, solving (A-16) with respect to $\ell$ gives the expression for the optimal $\ell$ given in the Proposition.

As to (A-17), solving it with respect to $n_{R}$ gives

$$
\hat{n}_{R}=\frac{5 \delta t n_{A}+\sqrt{\delta t n_{A}\left\{25 \delta t n_{A}+[48(1+\delta v-\ell)-60 \delta \ell]\left(n_{A}+1\right)\right\}}}{n_{A}[4(1+\delta v)-\ell(5 \delta+4)]},
$$

where none of the other solutions is admissible. Notice that $\hat{n}_{R} \geqslant 2$ when $t \geqslant t_{2}$.

It is easy to establish that $t_{1}<t_{2}$, by simply checking for the sign of their difference when $\delta$ goes to zero. Therefore, both in $t_{2}$ and (A-18), it is possible to substitute $\ell=0$ to obtain $t_{2}$ and the expression for the optimal $n_{R}$ given in the Proposition; similarly, in $t_{1}$, it 
is possible to substitute $n_{R}=2$ to obtain $t_{1}$ given in the Proposition.

Proof of Proposition 5. Let us initially assume $n_{R} \rightarrow \infty$. Then we can compute explicitly the optimal landing fee, which is given by $\left.\ell^{*}\right|_{n_{R} \rightarrow \infty}=\frac{1}{2}(1+\delta v)$, as indicated in the Proposition. Then the rest of the proof consists in showing that indeed it is optimal to set $n_{R} \rightarrow \infty$ for $\delta \geqslant 4 / 5$.

Using (A-15), we compute $\frac{\partial^{2} \Pi}{\partial n_{R} \partial v}$ : this takes a long expression, omitted here for the sake of brevity, which can be shown to be negative after substituting $\ell=\left.\ell^{*}\right|_{n_{R} \rightarrow \infty}$. Then, we can compute $\left.\frac{\partial \Pi}{\partial n_{R}}\right|_{v \rightarrow \infty}$ (using de l'Hôpital Rule), which constitutes a lower bound for $\frac{\partial \Pi}{\partial n_{R}}$. More precisely, $\left.\frac{\partial \Pi}{\partial n_{R}}\right|_{v \rightarrow \infty}=\frac{\delta n_{A}(5 \delta-4)}{8 n_{R}^{2}\left(n_{A}+1\right)}$, which is non-negative for $\delta \geqslant 4 / 5$. Therefore, $\frac{\partial \Pi}{\partial n_{R}}>0$ for $\delta \geqslant 4 / 5$, which directly implies $n_{R}^{*} \rightarrow \infty$.

When $\delta<4 / 5$, we first solve the system of equations given by (19) and (22) to obtain the second-stage equilibrium retail and aeronautical prices. These are given by

$$
\begin{aligned}
& p_{R}^{*}=\frac{4 n_{A} n_{R}^{2} \phi+3 \delta t n_{A} n_{R}+4 \delta t\left(n_{A}+1\right)-\sqrt{\psi}}{8 \delta n_{A} n_{R}^{2}}, \\
& p_{A}^{*}=\frac{2 n_{A} n_{R}^{2} \ell\left(n_{A}+1\right)-5 \delta t n_{A} n_{R}-4 \delta t\left(n_{A}+1\right)+\sqrt{\psi}}{8 n_{A} n_{R}^{2}\left(n_{A}+1\right)}
\end{aligned}
$$

where $\phi \equiv 1+\delta v-\ell$ and $\psi \equiv 16 \phi^{2} n_{A}^{2} n_{R}^{4}-40 \delta t \phi n_{A}^{2} n_{R}^{3}+\delta t n_{A} n_{R}^{2}\left[25 \delta t n_{A}+32 \phi\left(n_{A}+1\right)\right]+$ $24 \delta^{2} t^{2} n_{A} n_{R}\left(n_{A}+1\right)+16 \delta^{2} t^{2}\left(1+n_{A}^{2}+2 n_{A}\right)$. These are then plugged into the airport's profit, which is maximized with respect to $n_{R}$ and $\ell$. The resulting analytical expressions are not reported given their complexity. For a given constellation of parameter values, we obtained the plots shown in the figures. We also checked that all the relevant non-negativity constraints are met, namely for quantities in the airline market and for the consumer surplus in the retail market.

Proof of Proposition 6. From Proposition 3, $\left.\pi^{*}\right|_{\delta=0}=\frac{n_{A}(t+2)^{2}}{16\left(n_{A}+1\right)}$ when $t<2$, and $\left.\pi^{*}\right|_{\delta=0}=$ $\frac{t n_{A}}{2\left(n_{A}+1\right)}$ when $t \geqslant 2$. Similarly, from Proposition $5,\left.\pi^{*}\right|_{\delta \geqslant \frac{4}{5}}=\frac{n_{A}(1+\delta v)^{2}}{4\left(n_{A}+1\right)}$, which is clearly increasing in $\delta$. Comparing the two profits, it obtains that $\left.\pi^{*}\right|_{\delta=0}>\left.\pi^{*}\right|_{\delta \geqslant \frac{4}{5}}$ when $v<\frac{t}{2 \delta}$ (when $t<2$ ) or $v<\frac{\sqrt{2 t}-1}{\delta}$ (when $t \geqslant 2$ ), where both limiting values are below the smallest admissible value for $v$, which is $\frac{5 t}{8}$, from (15). Hence the highest profit that can be achieved is $\left.\pi^{*}\right|_{\delta \geqslant \frac{4}{5}}$, in particular when $\delta=1$. Results on the absolute values of $\pi_{R}^{*}$ and $\pi_{A}^{*}$ follow directly from Propositions 3 and 5 .

As for the results for $\delta$ around 0, using the envelope theorem, we simply take the derivative of the airport's profits with respect to $\delta$, plug into it the optimal values $\left.\ell^{*}\right|_{\delta=0}$ and $\left.n_{R}^{*}\right|_{\delta=0}$ and evaluate it at $\delta=0$. This gives $\left.\frac{\partial \pi^{*}}{\partial \delta}\right|_{\delta=0}=\frac{8 v n_{A}(t+2)-t\left(9 t n_{A}+10 n_{A}+4 t\right)}{32\left(n_{A}+1\right)}$, $\left.\frac{\partial \pi_{R}^{*}}{\partial \delta}\right|_{\delta=0}=\frac{t\left[8 v n_{A}-t\left(7 n_{A}+2\right)\right]}{16\left(n_{A}+1\right)}$, and $\left.\frac{\partial \pi_{A}^{*}}{\partial \delta}\right|_{\delta=0}=\frac{n_{A}[(8 v-5 t)(2-t)]}{32\left(n_{A}+1\right)}$ when $t<2 ;$ and $\left.\frac{\partial \pi^{*}}{\partial \delta}\right|_{\delta=0}=$ 
$\left.\frac{\partial \pi_{R}^{*}}{\partial \delta}\right|_{\delta=0}=\frac{t\left[8 v n_{A}-t\left(7 n_{A}+2\right)\right]}{16\left(n_{A}+1\right)}$ and $\left.\frac{\partial \pi_{A}^{*}}{\partial \delta}\right|_{\delta=0}=0$ when $t \geqslant 2$. Solving these expressions with respect to $v$ gives the critical values and the results in the Proposition.

\section{Appendix B: Proportional preferences in the general platform model}

In this Appendix, we make explicit the microeconomic foundations for the demand specification we use in Section 3.

A representative consumer has a quasi-linear utility function $U\left(Q_{A}, Q_{R}, m\right)=u\left(Q_{A}, Q_{R}\right)+$ $m$, with $u\left(Q_{A}, Q_{R}\right)=g\left(Q_{A}\right)+\delta \Psi\left(Q_{A}, Q_{R}\right)$, where $Q_{A}$ and $Q_{R}$ are the quantities of the core and the side good and $m$ is the numeraire. The functions $g($.$) and \Psi($.$) denote the utility$ derived from the core and the side good, respectively. We assume $g(0)=0, g^{\prime}\left(Q_{A}\right)>0$, and $g^{\prime \prime}\left(Q_{A}\right)<0$. The function $\Psi\left(\right.$.) satisfies $\Psi(0,0)=0$ and $\Psi\left(0, Q_{R}\right)=\Psi\left(Q_{A}, 0\right)=0$. We consider the consumption of the side good to be proportional to that of the core good, an assumption that fits rather well with the nature of demand in the case of airports. Following Czerny and Lindsey (2014), this feature is captured assuming $\Psi\left(Q_{A}, Q_{R}\right)$ to be homogeneous of degree one, so that it can be rewritten as $\Psi\left(Q_{A}, Q_{R}\right)=Q_{A} h\left(Q_{R} / Q_{A}\right)$ with $h^{\prime}\left(Q_{R} / Q_{A}\right)>0$ and $h^{\prime \prime}\left(Q_{R} / Q_{A}\right)<0$. Therefore, the consumer solves

$$
\max _{Q_{A}, Q_{R}} g\left(Q_{A}\right)-p_{A} Q_{A}+\delta\left[Q_{A} h\left(Q_{R} / Q_{A}\right)-p_{R} Q_{R}\right]
$$

and the FOC with respect to $Q_{R}$ yields $p_{R}=h^{\prime}\left(Q_{R} / Q_{A}\right)$. Define now the inverse function $y\left(p_{R}\right) \equiv\left(h^{\prime}\right)^{-1}\left(p_{R}\right)$. Then, the above FOC becomes $Q_{R}=y\left(p_{R}\right) Q_{A}$, as in (1); hence, the demand for good $R$ is proportional to the demand for good $A$, with $y^{\prime}\left(p_{R}\right)<0$.

Consumer's total surplus from the side good is $Q_{A} h\left(Q_{R} / Q_{A}\right)-p_{R} Q_{R}$, which can be rewritten as $Q_{A} C S\left(p_{R}\right)$, where $C S\left(p_{R}\right) \equiv\left[h\left(y\left(p_{R}\right)\right)-p_{R} y\left(p_{R}\right)\right]$ denotes the consumer surplus per unit consumed of core good. Thus, the consumer problem in (B-1) becomes

$$
\max _{Q_{A}} g\left(Q_{A}\right)+Q_{A}\left[\delta C S\left(p_{R}\right)-p_{A}\right]
$$

which yields the first-order condition in (3). 


\section{Online Appendix: The general platform model with heterogenous consumers}

In this Appendix we extend the model in Section 3 to account for the demand for good $R$ depending on consumers' personal characteristics (i.e., we introduce consumer heterogeneity). Following Czerny and Lindsey (2014), we let $\theta$ denote the consumer's type and we reinterpret the optimal choice of $Q_{R}$ derived in Section 3 as the individual demand for a consumer of type $\theta$. We now use small letters to denote individual quantities that depend on the consumer's type, while capital letters describe aggregate demand; we leave the rest of the set-up of the section unchanged. Therefore, the demand for good $R$ of type $\theta$ can be written as $q_{R}\left(p_{A}, p_{R} ; \theta\right)=y\left(p_{R} ; \theta\right) q_{A}(\theta)$, as in (1). Similarly, the optimal demand for good $A$ of type $\theta$ arises as the solution to

$$
\max _{q_{A}(\theta)} g\left[q_{A}(\theta)\right]+q_{A}(\theta)\left[\delta C S\left(p_{R} ; \theta\right)-p_{A}\right]
$$

which yields the following first-order condition

$$
g^{\prime}\left[q_{A}(\theta)\right]+\delta C S\left(p_{R} ; \theta\right)-p_{A}=0,
$$

that implicitly determines $q_{A}\left(p_{A}, p_{R} ; \theta\right)$. Then, the aggregate demand for good $A$ is

$$
Q_{A}\left(p_{A}, p_{R}\right)=\int_{\theta} q_{A}\left(p_{A}, p_{R} ; \theta\right) \phi(\theta) d \theta
$$

where $\phi(\theta)$ is the frequency distribution of types. Weighted in terms of consumption of $\operatorname{good} A$, the average consumption of $\operatorname{good} R$ is

$$
\bar{y}\left(p_{A}, p_{R}\right)=\frac{1}{Q_{A}\left(p_{A}, p_{R}\right)} \int_{\theta} q_{A}\left(p_{A}, p_{R} ; \theta\right) y\left(p_{R} ; \theta\right) \phi(\theta) d \theta
$$

which depends on $p_{R}$ (as before) but also on $p_{A}$. Therefore, the demand of good $R$ with respect to good $A$ becomes

$$
Q_{R}\left(p_{A}, p_{R}\right)=\bar{y}\left(p_{A}, p_{R}\right) Q_{A}\left(p_{A}, p_{R}\right)
$$

Turning now to the platform's problem, in the first stage it solves

$$
\begin{aligned}
& \max _{\ell, n_{R}}\left[\ell-c+p_{R} \bar{y}\left(p_{A}, p_{R}\right)\right] Q_{A}\left(p_{A}, p_{R}\right) \\
& \text { s.t. } p_{R}=p_{R}\left(\ell, n_{R}\right) \quad \text { and } \quad p_{A}=p_{A}\left(\ell, n_{R}\right),
\end{aligned}
$$


which yields the following first-order conditions (omitting the arguments of $Q_{A}$ to simplify notation)

$$
\begin{aligned}
\frac{\partial \Pi}{\partial \ell}= & \left(\frac{\partial Q_{A}}{\partial p_{A}} \frac{\partial p_{A}}{\partial \ell}+\frac{\partial Q_{A}}{\partial p_{R}} \frac{\partial p_{R}}{\partial \ell}\right)\left[\ell-c+p_{R} \bar{y}\left(p_{A}, p_{R}\right)\right] \\
& +Q_{A}\left[1+\frac{\partial p_{R}}{\partial \ell}\left(\bar{y}\left(p_{A}, p_{R}\right)+p_{R} \frac{\partial \bar{y}\left(p_{A}, p_{R}\right)}{\partial p_{R}}\right)+p_{R} \frac{\partial \bar{y}\left(p_{A}, p_{R}\right)}{\partial p_{A}} \frac{\partial p_{A}}{\partial \ell}\right]=0 \\
\frac{\partial \Pi}{\partial n_{R}}= & \left(\frac{\partial Q_{A}}{\partial p_{A}} \frac{\partial p_{A}}{\partial n_{R}}+\frac{\partial Q_{A}}{\partial p_{R}} \frac{\partial p_{R}}{\partial n_{R}}\right)\left[\ell-c+p_{R} \bar{y}\left(p_{A}, p_{R}\right)\right] \\
& +Q_{A}\left[\frac{\partial p_{R}}{\partial n_{R}}\left(\bar{y}\left(p_{A}, p_{R}\right)+p_{R} \frac{\partial \bar{y}\left(p_{A}, p_{R}\right)}{\partial p_{R}}\right)+p_{R} \frac{\partial \bar{y}\left(p_{A}, p_{R}\right)}{\partial p_{A}} \frac{\partial p_{A}}{\partial n_{R}}\right] \leqslant 0 .
\end{aligned}
$$

In studying these first-order conditions, notice first that heterogeneity in the consumers' preferences implies that $\frac{\partial p_{R}}{\partial \ell} \lesseqgtr 0$, since a change in $\ell$ can alter the composition of demand in the side good market. Consider for instance a decrease in $\ell$. In this case, $p_{A}$ would also go down (see (6)) and, therefore, the equilibrium $Q_{A}$ would increase. However, the effect of this increase in the demand for good $A$ may have different effects on market $R$, depending on the effect on $R$ 's demand composition as a response to the lower $\ell$. For instance, the case $\frac{\partial p_{R}}{\partial \ell}>0$ may be possible if the demand for side good goes down and translates into a lower $p_{R}$.

Using (5) and (6), equation (8) can be re-expressed as

$$
\begin{aligned}
\frac{\ell-\left[c-p_{R} \bar{y}\left(p_{A}, p_{R}\right)\right]}{\ell}= & -\frac{1}{\epsilon_{A} \sigma_{A \ell}+\epsilon_{A R} \sigma_{R \ell}} \times \\
& \underbrace{\left[1+\frac{\partial p_{R}}{\partial \ell}\left[\bar{y}\left(p_{A}, p_{R}\right)+p_{R} \frac{\partial \bar{y}\left(p_{A}, p_{R}\right)}{\partial p_{R}}\right]+p_{R} \frac{\partial \bar{y}\left(p_{A}, p_{R}\right)}{\partial p_{A}} \frac{\partial p_{A}}{\partial \ell}\right]}_{\Omega},
\end{aligned}
$$

where the left-hand side and the first term on the right-hand side (containing the superelasticities) are as in the representative consumer case. Similarly to the analogous expression with a representative consumer, $\bar{y}\left(p_{A}, p_{R}\right)+p_{R} \frac{\partial \bar{y}\left(p_{A}, p_{R}\right)}{\partial p_{R}}>0$ captures now the marginal revenue in the secondary market with respect to $p_{R}$, calculated at the average level of good $R$. The main novelty with respect to the representative consumer case is the presence of the term $p_{R} \frac{\partial \bar{y}\left(p_{A}, p_{R}\right)}{\partial p_{A}} \frac{\partial p_{A}}{\partial \ell}$, which captures the reaction of market $R$ 's demand composition as a response to a change $\ell$ and, therefore, has an indeterminate sign. This demand composition effect in the side-good market also determines the sign of $\frac{\partial p_{R}}{\partial \ell}$. Therefore, depending on the signs of $\frac{\partial \bar{y}\left(p_{A}, p_{R}\right)}{\partial p_{A}}$ and $\frac{\partial p_{R}}{\partial \ell}$, we may observe $\Omega \lessgtr 0$ and different cases can be analyzed.

For instance, let us consider the case of a decrease in $\ell$ that pushes down $p_{A}$ (see $\left.(6)\right)$ 
and yields a higher equilibrium $Q_{A}$. If market $R$ 's demand composition effect is such that the demand for side good goes up in a less-than-proportional way, then we would obtain $\frac{\partial \bar{y}\left(p_{A}, p_{R}\right)}{\partial p_{A}}<0$ and $\frac{\partial p_{R}}{\partial \ell}<0$. If the combination of these effects is sufficiently large, then $\Omega<0$. The other cases can be reasoned analogously.

Independently of the sign of $\Omega$, it can be easily observed that the degree of consumer foresight only affects (W-9) through $\epsilon_{A R}$. As in the representative consumer case, $-\left(\epsilon_{A} \sigma_{A \ell}+\epsilon_{A R} \sigma_{R \ell}\right)<0$ is observed for a sufficiently high $\delta$. Therefore, when $\Omega<0$, the platform's optimal choice of $\ell$ is increasing with the degree of consumer foresight. When. instead, $\Omega \geqslant 0$ is observed, the platform sets $\ell$ equal or below the adjusted marginal cost and foresight has no effect. In conclusion, the effect of consumer foresight on the platform's optimal choice of $\ell$ will be either positive or inexistent, depending on the demand composition effect in the side good market.

Substituting (W-9) into (W-8), using (5) and (6) and rearranging, one obtains

$$
\frac{\partial p_{R}}{\partial n_{R}}\left[\bar{y}\left(p_{A}, p_{R}\right)+p_{R} \frac{\partial \bar{y}\left(p_{A}, p_{R}\right)}{\partial p_{R}}\right]+p_{R} \frac{\partial \bar{y}\left(p_{A}, p_{R}\right)}{\partial p_{A}} \frac{\partial p_{A}}{\partial n_{R}}-\frac{\epsilon_{A} \sigma_{A n}+\epsilon_{A R} \sigma_{R n}}{\epsilon_{A} \sigma_{A \ell}+\epsilon_{A R} \sigma_{R \ell}} \frac{\ell}{n_{R}} \Omega \leqslant 0 .
$$

The degree of consumer foresight only affects (W-10) through its last term and, as in the representative consumer case, $-\frac{\ell}{n_{R}} \frac{\epsilon_{A} \sigma_{A n}+\epsilon_{A R} \sigma_{R n}}{\epsilon_{A} \sigma_{A \ell}+\epsilon_{A R} \sigma_{R \ell}}<0$ is observed for sufficiently high levels of $\delta$. In this case, when $\Omega<0$, the platform's optimal choice of $n_{R}$ is increasing with the degree of consumer foresight. Whenever $\Omega \geqslant 0$ is observed, high levels of $\delta$ could yield lower levels of $n_{R} \cdot{ }^{25}$

All in all, the presence of consumer heterogeneity turns the analysis more complicated due to the presence of market $R$ 's demand composition effect as a response to a change in $\ell$. However, the effect of consumer foresight on the platform's choices can still be analyzed. We show that the results found with a representative consumer are partly confirmed with consumers' heterogeneity. Indeed, under both scenarios, consumers' foresight pushes up the price of the input in market $A$. On the other hand, no clear-cut conclusions can be reached for the effect of foresight on the market structure of the side good. The driving force leading to this indeterminate result is precisely the demand composition effect that, with heterogenous consumers, may affect the demand for the core good in both directions.

\footnotetext{
${ }^{25}$ In the case of fully-myopic consumers $(\delta=0)$, then $\frac{\partial Q_{A}}{\partial p_{R}}$ and $\frac{\partial p_{A}}{\partial n_{R}}=0$ and, as a consequence, $\epsilon_{A R}=0$ and $\sigma_{A n}=0$. Therefore, $(\mathrm{W}-10)$ reduces to $\frac{\partial p_{R}}{\partial n_{R}}\left[\bar{y}\left(p_{A}, p_{R}\right)+p_{R} \frac{\partial \bar{y}\left(p_{A}, p_{R}\right)}{\partial p_{R}}\right]+p_{R} \frac{\partial \bar{y}\left(p_{A}, p_{R}\right)}{\partial p_{A}} \frac{\partial p_{A}}{\partial n_{R}} \leqslant 0$, where the first term is negative and the second one depends on the sign of the demand composition effect in the side-good market through $\frac{\partial \bar{y}\left(p_{A}, p_{R}\right)}{\partial p_{A}}$. In consequence, $n_{R}$ can be set either at its minimum level or at a higher value.
} 